\title{
Deuterium exchange as an indicator of hydrogen bond donors and acceptors
}

Lauren R. Steffel, Timothy J. Cashman, Michael H. Reutershan and Brian R. Linton Department of Chemistry, Bowdoin College, Brunswick, ME 04011

\section{Supporting Information}

General Procedures. Proton NMR were recorded on a Bruker 400 spectrometer. Proton chemical shifts are reported in ppm ( $\delta$ ) relative to internal tetramethylsilane (TMS, $\delta 0.0$ $\mathrm{ppm}$ ), or with the solvent reference relative to TMS employed as an internal standard $\left(\mathrm{CDCl}_{3}, \delta 7.26 \mathrm{ppm}\right)$. Data are reported as follows: chemical shift (multiplicity [singlet (s), doublet (d), triplet (t), quartet (q), multiplet (m)], coupling constant [Hz], integration). Carbon NMR spectra were recorded on either a Bruker $400(100 \mathrm{MHz})$ spectrometer with complete proton decoupling. Carbon chemical shifts are reported in ppm ( $\delta$ ) relative to TMS with the respective solvent resonance as the internal standard $\left(\mathrm{CDCl}_{3}, \delta 77.23\right.$ $\mathrm{ppm})$. Spectra for synthetic characterization were recorded at ambient temperature, while kinetic analyses were performed at $23^{\circ} \mathrm{C}$. Flash column chromatography was performed using Silica Gel $60 \AA$ (32-63 micron). ${ }^{1}$ Synthetic yields are not optimized. High resolution mass spectra were acquired using a HiResMALDI Fourier transform mass spectrometer at Bowdoin College (Brunswick, ME). 


\section{Synthetic Procedures:}

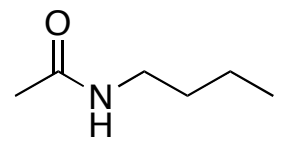

N-butylethanamide (1). Butylamine (313 mg, $4.29 \mathrm{mmol})$, acetic anhydride (657 mg, $6.44 \mathrm{mmol})$ and triethylamine (650 mg, 6.44 mmol) were dissolved in $20 \mathrm{~mL}$ dichloromethane. After stirring overnight, the solution was washed with $10 \% \mathrm{HCl}$, sat $\mathrm{NaHCO}_{3}$, dried over $\mathrm{Na}_{2} \mathrm{SO}_{4}$ and evaporated to dryness under reduced pressure to yield $110 \mathrm{mg}(22 \%)$ of a clear oil. ${ }^{1} \mathrm{H}$ NMR $\delta 7.00(\mathrm{~s}, 1 \mathrm{H}), 3.21(\mathrm{~m}, 2 \mathrm{H}), 1.98(\mathrm{~s}, 3 \mathrm{H}), 1.48(\mathrm{~m}, 2 \mathrm{H}), 1.35(\mathrm{~m}, 2 \mathrm{H}), 0.92(\mathrm{t}, J=$ 7.2 Hz, 3H); ${ }^{13} \mathrm{C}$ NMR $\delta 170.4,39.2,31.4,22.9,20.0,13.6$; MS (EI): $115(\mathrm{M}+, 43), 100$ (75), 86 (45), 73 (100), $72(99), 60$ (26).<smiles>CCCCNC(=O)CC</smiles>
$N$-butylpropanamide (2). Propanoic acid (100 mg, $1.35 \mathrm{mmol}$ ) was mmol) and butylamine (109 mg, $1.49 \mathrm{mmol})$. After stirring overnight, the solution was washed with $10 \% \mathrm{HCl}$, sat $\mathrm{NaHCO}_{3}$, dried over $\mathrm{Na}_{2} \mathrm{SO}_{4}$ and evaporated to dryness under reduced pressure to yield $97 \mathrm{mg}(56 \%)$ of a clear oil. ${ }^{1} \mathrm{H}$ NMR $\delta 6.65(\mathrm{br}, 1 \mathrm{H}), 3.22$ (q, $J$ $=7.2 \mathrm{~Hz}, 2 \mathrm{H}), 2.22(\mathrm{q}, J=7.6,2 \mathrm{H}), 1.50(\mathrm{~m}, 2 \mathrm{H}), 1.34(\mathrm{~m}, 2 \mathrm{H}) 1.15(\mathrm{t}, J=7.6,3 \mathrm{H}), 0.92$ $(\mathrm{t}, J=7.2,3 \mathrm{H}) ;{ }^{13} \mathrm{C}$ NMR $\delta 174.2,39.1,31.6,29.5,20.0,13.7,10.0$; MS (EI): 129 (M+, 24), 114 (13), 100 (65), 87 (69), 86 (54), 74 (22), 57 (100).

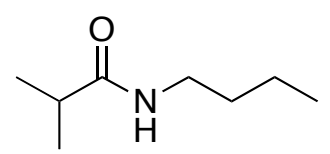

N-butyl-2-methylpropanamide (3). Isobutyric acid (200 mg, 2.27 mmol) was dissolved in $20 \mathrm{~mL}$ dichloromethane along with EDCI (480 mg, $2.50 \mathrm{mmol}$ ) and butylamine (182 mg, $2.50 \mathrm{mmol})$. After stirring for 5 hours, the solution was washed with $10 \% \mathrm{HCl}$, sat $\mathrm{NaHCO}_{3}$, dried over $\mathrm{Na}_{2} \mathrm{SO}_{4}$ and evaporated to dryness under reduced pressure to yield $178 \mathrm{mg}(55 \%)$ of a clear oil. ${ }^{1} \mathrm{H}$ NMR $\delta 5.91(\mathrm{br}, 1 \mathrm{H}), 3.23(\mathrm{q}, J=6.6 \mathrm{~Hz}, 2 \mathrm{H}), 2.37$ (m, 1H), 1.49 (m, 2H), $1.34(\mathrm{~m}, 2 \mathrm{H}), 1.14(\mathrm{~d}, J=6.9 \mathrm{~Hz}, 6 \mathrm{H}), 0.92(\mathrm{t}, J=7.3 \mathrm{~Hz}, 3 \mathrm{H}) ;{ }^{13} \mathrm{C}$ NMR $\delta 177.2,39.2$, 35.7, 31.9, 20.2, 19.8, 13.9; MS (EI): 143 (M+, 43), 128 (28), 114 (14), 101(59), 100 (60), 88 (24), 73 (31), 72 (68), 71 (100), 57 (100). 


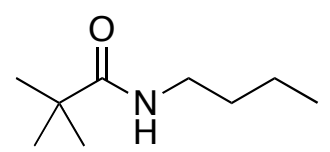

$\mathrm{N}$-butyl-2,2-dimethylpropanamide (4). Trimethylacetic acid (100 $\mathrm{mg}, 0.98 \mathrm{mmol}$ ) was dissolved in $20 \mathrm{~mL}$ dichloromethane along with EDCI (225 mg, $1.17 \mathrm{mmol})$ and butylamine (79 mg, 1.08

mmol). After stirring for 16 hours, the solution was washed with $10 \% \mathrm{HCl}$, sat $\mathrm{NaHCO}_{3}$, dried over $\mathrm{Na}_{2} \mathrm{SO}_{4}$ and evaporated to dryness under reduced pressure to yield $75 \mathrm{mg}$ (49\%) of a clear oil. ${ }^{1} \mathrm{H}$ NMR $\delta 5.64(\mathrm{br}, 1 \mathrm{H}), 3.23(\mathrm{~m}, 2 \mathrm{H}), 1.49(\mathrm{~m}, 2 \mathrm{H}), 1.33(\mathrm{~m}, 2 \mathrm{H})$, 1.20 (s, 9H), $0.92(\mathrm{t}, J=7.2 \mathrm{~Hz}, 3 \mathrm{H}) ;{ }^{13} \mathrm{C}$ NMR $\delta 178.5,39.5,38.8,31.9,27.8,20.3$, 14.0; MS (EI): 157 (M+, 15), 142 (9), 128 (4), 115 (14), 114 (10), 102 (14), 100 (14) 85 (16), 73 (7), 57 (100).

N $\begin{aligned} & \mathrm{N} \text {-isopropylethanamide (5). Isopropylamine (318 mg, } 5.38 \mathrm{mmol}) \text {, acetic } \\ & \text { anhydride }(500 \mathrm{mg}, 4.9 \mathrm{mmol}) \text { and triethylamine }(545 \mathrm{mg}, 5.40 \mathrm{mmol}) \text { were }\end{aligned}$ dissolved in $20 \mathrm{~mL}$ dichloromethane. After stirring overnight, the solution was washed with $10 \% \mathrm{HCl}$, sat $\mathrm{NaHCO}_{3}$, dried over $\mathrm{Na}_{2} \mathrm{SO}_{4}$ and evaporated to dryness under reduced pressure to yield $33 \mathrm{mg}(7 \%)$ of a pale oil. ${ }^{1} \mathrm{H}$ NMR $\delta 5.43(\mathrm{br}, 1 \mathrm{H}), 4.07(\mathrm{~m}, 1 \mathrm{H}), 1.95$ (s, 3H), 1.15 (d, $J=6.5 \mathrm{~Hz}, 6 \mathrm{H}) ;{ }^{13} \mathrm{C}$ NMR $\delta$ 169.4, 41.6, 23.7, 23.0; MS (EI): 101 (M+, 100), $86(66), 58(31)$.

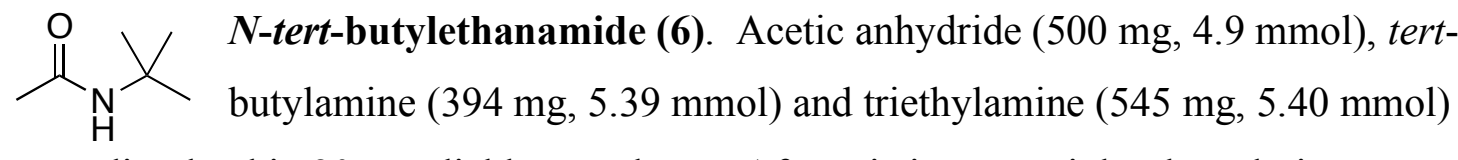
were dissolved in $20 \mathrm{~mL}$ dichloromethane. After stirring overnight, the solution was washed with $10 \% \mathrm{HCl}$, sat $\mathrm{NaHCO}_{3}$, dried over $\mathrm{Na}_{2} \mathrm{SO}_{4}$ and evaporated to dryness under reduced pressure to yield $131 \mathrm{mg}$ (22\%) of a white solid. ${ }^{1} \mathrm{H}$ NMR $\delta 6.39(\mathrm{br}, 1 \mathrm{H}), 1.92$ (s, 3H), 1.365 (s, 9H); ${ }^{13} \mathrm{C}$ NMR $\delta$ 169.7, 50.8, 28.6, 24.1; MS (EI): 115 (M+, 23), 100 (26), $58(100)$.

$>$ tert-butyl butylcarbamate (7). ${ }^{2}$ Butylamine (200mg, 1.37 hydroxide dihydrate (124 mg, $1.37 \mathrm{mmol}$ ) dissolved in $5 \mathrm{~mL}$ water. To this turbid mixture was added solid di-tert-butyl dicarbonate $(600 \mathrm{mg}, 3.00 \mathrm{mmol})$ and the solution was stirred overnight. The reaction was partitioned between dichloromethane and 10\% 
citric acid, and the organic layer was dried over $\mathrm{Na}_{2} \mathrm{SO}_{4}$ and evaporated to dryness under reduced pressure to yield $424 \mathrm{mg}(89 \%)$ of a clear oil. ${ }^{1} \mathrm{H}$ NMR $\delta 4.81(\mathrm{br}, 1 \mathrm{H}), 3.11(\mathrm{~m}$, 2H), $1.44(\mathrm{~s}, 11 \mathrm{H}), 1.33(\mathrm{~m}, 2 \mathrm{H}), 0.92(\mathrm{t}, J=7.2 \mathrm{~Hz}, 3 \mathrm{H}) ;{ }^{13} \mathrm{C}$ NMR $\delta$ 155.8, 77.9, 39.8, 31.8, 27.9, 19.5, 13.3; MS (EI): 173 (M+, 1), 130 (1), 118 (23), 117 (15), 59 (34), $57(100)$.<smiles>CC(C)NC(=O)OC(C)(C)C</smiles>

tert-butyl isopropylcarbamate (8). ${ }^{3}$ Isopropylamine (200 mg, 3.39 $\mathrm{mmol}$ ) was dissolved in $10 \mathrm{~mL}$ acetonitrile. Tetrabutylammonium hydroxide (614 mg, $3.39 \mathrm{mmol}$ ) was added as a suspension and stirred for one hour. Ditert-butyl dicarbonate $(900 \mathrm{mg}, 4.12 \mathrm{mmol})$ was added and the solution was stirred for two days. The solvent was removed in vacuo and the residue partitioned between $\mathrm{Et}_{2} \mathrm{O}$ and $\mathrm{H}_{2} \mathrm{O}$. The water layer was washed twice $\mathrm{Et}_{2} \mathrm{O}$ and the combined organic fractions were dried over $\mathrm{Na}_{2} \mathrm{SO}_{4}$ and evaporated to dryness under reduced pressure to yield 426 mg (79\%) of a white solid. ${ }^{1} \mathrm{H}$ NMR $\delta 4.76(\mathrm{br}, 1 \mathrm{H}), 3.76(\mathrm{br}, 1 \mathrm{H}), 1.44(\mathrm{~s}, 9 \mathrm{H}), 1.13$ (d, $J=6.4,6 \mathrm{H}) ;{ }^{13} \mathrm{C}$ NMR $\delta 155.1,78.5,42.3,28.3,22.9$; MS (EI): 159 (M+, 1), 144 (20), 104 (27), 88 (11), 59 (41), 57 (100).<smiles>CC(C)(C)NC(=O)OC(C)(C)C</smiles>
tert-butyl tert-butylcarbamate (9). ${ }^{3}$ t-butylamine (200 mg, 2.73 $\mathrm{mmol}$ ) was dissolved in $10 \mathrm{~mL}$ acetonitrile. Tetrabutylammonium hydroxide (500 mg, $2.76 \mathrm{mmol}$ ) was added as a suspension and stirred for one hour. Ditert-butyl dicarbonate $(900 \mathrm{mg}, 4.12 \mathrm{mmol}$ ) was added and the solution was stirred for two days. The solvent was removed in vacuo and the residue partitioned between $\mathrm{Et}_{2} \mathrm{O}$ and $\mathrm{H}_{2} \mathrm{O}$. The water layer was washed twice $\mathrm{Et}_{2} \mathrm{O}$ and the combined organic fractions were dried over $\mathrm{Na}_{2} \mathrm{SO}_{4}$ and evaporated to dryness under reduced pressure to yield 345 mg (73\%) of a white solid. ${ }^{1} \mathrm{H}$ NMR $\delta 4.70(\mathrm{br}, 1 \mathrm{H}), 1.432(\mathrm{~s}, 9 \mathrm{H}), 1.30(\mathrm{~s}, 9 \mathrm{H}) ;{ }^{13} \mathrm{C}$ NMR $\delta$ 154.4, 78.2, 49.8, 28.9, 28.3; MS (EI): 173 (M+, 1), 158 (11), 118 (3), 102 (21), $59(17), 58(42), 57(100)$.

年 ${ }_{3}{ }_{\mathrm{H}}^{\mathrm{N} \text {-tert-butyl-2,2,2-trifluoroethanamide (10). Trifluoroacetic anhydride }}$ dissolved in $10 \mathrm{~mL}$ dichloromethane. After stirring overnight, the solution was washed 
with $10 \%$ citric acid, sat $\mathrm{NaHCO}_{3}$, dried over $\mathrm{Na}_{2} \mathrm{SO}_{4}$ and evaporated to dryness under aspirator pressure to yield $100 \mathrm{mg}(62 \%)$ of a white solid. ${ }^{1} \mathrm{H}$ NMR $\delta 6.34(\mathrm{~s}, 1 \mathrm{H}), 1.42$ (s, 9H); ${ }^{13} \mathrm{C}$ NMR $\delta 157.7$ (q, $\left.J=36 \mathrm{~Hz}\right), 116.1$ (q, $\left.J=286 \mathrm{~Hz}\right), 39.9,30.9,20.0,13.6$; MS (EI): 169 (M+, 1), 154 (100), 114 (23), 94 (5), 84 (6), 69 (20), 59 (24), 57(14), 56 (15).

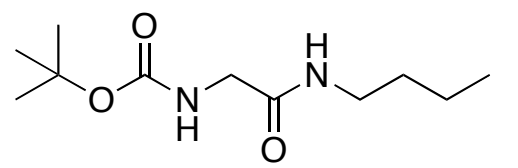

Boc-Gly-NHBu (11). Boc-glycine (250 mg, $1.43 \mathrm{mmol})$ was dissolved in $20 \mathrm{~mL}$ dichloromethane along with hydroxybenztriazole ( $218 \mathrm{mg}, 1.42 \mathrm{mmol}$ ), EDCI (328 $\mathrm{mg}, 1.71 \mathrm{mmol})$ and butylamine $(115 \mathrm{mg}, 1.58 \mathrm{mmol})$. After stirring overnight, the solution was washed with $10 \% \mathrm{HCl}$, sat $\mathrm{NaHCO}_{3}$, dried over $\mathrm{Na}_{2} \mathrm{SO}_{4}$ and evaporated to dryness under reduced pressure to yield $300 \mathrm{mg}(91 \%)$ of a clear oil. ${ }^{1} \mathrm{H}$ NMR $\delta 7.17(\mathrm{br}$, 1H, $\mathrm{N} \underline{\mathrm{H}}-\mathrm{Bu}), 6.10(\mathrm{br}, 1 \mathrm{H}, \alpha-\mathrm{N} \underline{\mathrm{H}}), 3.79(\mathrm{~m}, 2 \mathrm{H}), 3.25(\mathrm{~m}, 2 \mathrm{H}), 1.44(\mathrm{~s}, 11 \mathrm{H}), 1.35(\mathrm{~m}$, $2 \mathrm{H}), 0.91(\mathrm{t}, J=7.2,3 \mathrm{H}) ;{ }^{13} \mathrm{C}$ NMR $\delta 169.8,156.2,79.5,43.9,39.0,31.3,28.1,19.8$, 13.5; MS (EI): 230 (M+, 1), 174 (30), 157 (38), 131 (15), 100 (20), 75 (57), 57(100).

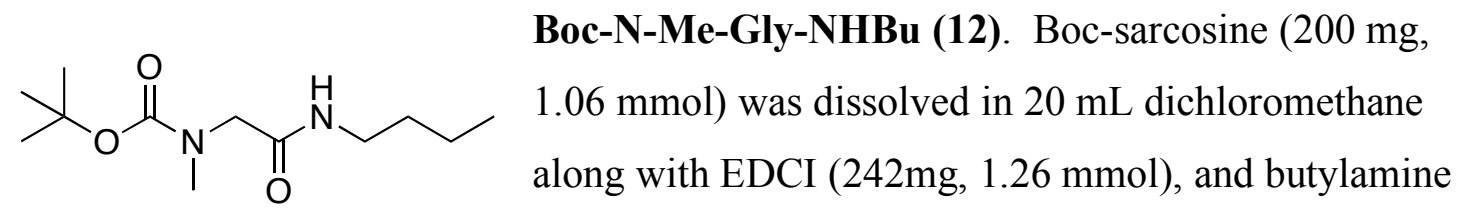
(85 mg, $1.06 \mathrm{mmol}$ ). After stirring overnight, the solution was washed with $10 \% \mathrm{HCl}$, sat $\mathrm{NaHCO}_{3}$, dried over $\mathrm{Na}_{2} \mathrm{SO}_{4}$ and evaporated to dryness under reduced pressure to yield $210 \mathrm{mg}$ of a white solid, which was recrystallized by dissolving in $2 \mathrm{~mL}$ dichloromethane, adding $20 \mathrm{~mL}$ hexanes and allowing to sit in the freezer overnight yielding $181 \mathrm{mg}(70 \%)$ white crystals. ${ }^{1} \mathrm{H}$ NMR $\delta 6.49$ (br, 1H), 3.95 (br, 1H), 2.99 (s, 6H), 1.45 (s, 9H); ${ }^{13} \mathrm{C}$ NMR $\delta 169.1,156.3,80.3,52.9,389,35.6,31.5,28.1,19.8,13.6$; MS (EI): 244 (M+, 3), 188 (52), 171 (29), 145 (14), 144 (19), 143 (10), 115 (16), 112 (13), 110 (14), 89 (44), 57(100).<smiles>CC(C)COC(=O)NCC(=O)N(C)C</smiles> 
$6.26 \mathrm{mmol})$, dimethylamine hydrochloride $(512 \mathrm{mg}, 6.28 \mathrm{mmol})$ and diisopropylethylamine $(1.62 \mathrm{~g}, 12.53 \mathrm{mmol})$. After stirring overnight, the solution was washed with $10 \% \mathrm{HCl}$, sat $\mathrm{NaHCO}_{3}$, dried over $\mathrm{Na}_{2} \mathrm{SO}_{4}$ and evaporated to dryness under reduced pressure to yield $760 \mathrm{mg}(66 \%)$ of a white solid. ${ }^{1} \mathrm{H}$ NMR $\delta 5.66(\mathrm{br}, 1 \mathrm{H}), 3.95$ (br, 1H), 2.99 (s, 6H), 1.45 (s, 9H); ${ }^{13} \mathrm{C}$ NMR $\delta 168.4,155.9,79.3,42.3,35.9,35.5,28.4$; MS (EI): 203 (M+1, 1), 146 (100), 129 (60), 102 (13), 72 (95), 57(100).<smiles>CC(=O)NCCNC(=O)OCC(C)C</smiles>

tert-butyl 2-ethanamidoethylcarbamate (14). N-Boc-

ethylenediamine (104 mg, $0.65 \mathrm{mmol}$ ) was dissolved in $20 \mathrm{~mL}$ dichloromethane along with acetic anhydride $(80 \mathrm{mg}, 0.78$ mmol) and triethylamine ( $80 \mathrm{mg}, 0.79 \mathrm{mmol}$ ). After stirring overnight, the solution was washed with $10 \% \mathrm{HCl}$, sat $\mathrm{NaHCO}_{3}$, dried over $\mathrm{Na}_{2} \mathrm{SO}_{4}$ and evaporated to dryness under reduced pressure to yield $83 \mathrm{mg}(63 \%)$ of an off-white solid. ${ }^{1} \mathrm{H}$ NMR $\delta 6.64(\mathrm{br}, 1 \mathrm{H})$, 5.27 (br, 1H), 3.35 (m, 2H), 3.27 (m, 2H), 1.98 (s, 3H), 1.44 (s, 9H); ${ }^{13} \mathrm{C}$ NMR $\delta$ 171.2, 157.1, 79.8, 40.8, 40.4, 28.5, 23.3; MS (EI): 202 (M+1, 1), 146 (21), 143 (21), 129 (18), 115 (8), 87 (83), 73 (84), 57 (100).<smiles>CCCCNC(=O)CNC(=O)CNC(=O)OC(C)(C)C</smiles>
Boc-Gly-Gly-NHBu (15). Boc-Gly-NHBu 11 was dissolved in $1 \mathrm{~mL}$ dichloromethane and $1 \mathrm{~mL}$ trifluoroacetic acid. After stirring for two hours, the solution was concentrated under reduced pressure. The residue was dissolved in 10 $\mathrm{mL}$ dichloromethane along with a solution of Boc-Gly-OH (50 mg, $0.29 \mathrm{mmol}$ ), hydroxybenztriazole ( $39 \mathrm{mg}, 0.26 \mathrm{mmol})$, EDCI $(60 \mathrm{~m} \mathrm{mg}, 0.31 \mathrm{mmol})$ that had been premixed for $15 \mathrm{~min}$. N,N-diisopropylethylamine $(73 \mathrm{mg}, 0.56 \mathrm{mmol})$ was added and the solution was stirred overnight. The solution was washed with $10 \% \mathrm{HCl}$, sat $\mathrm{NaHCO}_{3}$, dried over $\mathrm{Na}_{2} \mathrm{SO}_{4}$ and evaporated to dryness under reduced pressure to yield $38 \mathrm{mg}$ (52\%) of a white solid. ${ }^{1} \mathrm{H}$ NMR $\delta 7.37$ (br, 1H), 6.87 (br, 1H), 5.68 (br, 1H), 3.94 (d, $J=$ $5.5 \mathrm{~Hz}, 2 \mathrm{H}), 3.83(\mathrm{~d}, J=5.6 \mathrm{~Hz}, 2 \mathrm{H}), 3.23(\mathrm{dt}, J=6.9,6.5 \mathrm{~Hz}, 2 \mathrm{H}), 1.49$ (m, 2H), 1.45 (s, 9H), $1.33(\mathrm{~m}, 2 \mathrm{H}), 0.91(\mathrm{t}, J=7.3 \mathrm{~Hz}, 3 \mathrm{H}) ;{ }^{13} \mathrm{C}$ NMR $\delta 171.0,169.4,156.8,80.3$, 44.2, 42.7, 39.4, 31.2, 28.2, 19.9, 13.6; HRMS (MALDI) calcd. for $\left[\mathrm{C}_{13} \mathrm{H}_{25} \mathrm{~N}_{3} \mathrm{O}_{4} \mathrm{Na}\right]$ requires $m / z 310.17373$, observed 310.17490 . 


\section{General procedure for H/D exchange:}

An initial NMR spectra was acquired with $450 \mu \mathrm{L}$ of an analyte solution with a concentration of $11.11 \mathrm{mM}$ in $\mathrm{CDCl}_{3}$. To this was added $50 \mu \mathrm{L}$ of $\mathrm{CD}_{3} \mathrm{OD}$ marking time $=0$. This procedure resulted in a final substrate concentration of $10 \mathrm{mM}$, which was well below the concentrations where any evidence of aggregation has been observed. The added methanol created a 10\% methanol:chloroform solution, with the final methanol concentration of $2.47 \mathrm{M}$, which ensured pseudo-first-order kinetics. For a typical experiment, spectra were acquired at 2, 4, 7, 10 minutes, then every 5 minutes through 100 minutes, at 120, 150 and 200 minutes, and then every 100 minutes thereafter until the disappearance of the proton signal into the baseline. If signals persisted beyond 2500 minutes, spectra were acquired every 1500 minutes ( $25 \mathrm{hrs})$. To minimize variability, a constant baseline correction was applied. Integration ranges for exchanging protons are user-defined and self-consistent within each experiment. A distinct non-exchanging signal was used as an internal integration reference. Rate constants (and corresponding half-lives) were determined from the slope of a nonlinear least squares fit to the graph of $A_{t}=A_{o} \exp (-k t)$. Rather than estimate the values at extended time, curve fits were performed using data that was $<90 \%$ exchanged. The y-intercept is taken as the calculated value at time zero, and this value is used to normalize the final data to a range from $100-0 \%$ hydrogen remaining. Analyses are the average of at least two runs acquired on non-successive days, with different solvents to ensure reproducibility. Errors are reported as the standard deviation among individual rate constants or half-lives. Rates were found to be dependent on solvent and substrate purity. Fresh ampules of methanol$\mathrm{d}_{4}$ were opened weekly, and fresh chloroform-d stored over activated molecular sieves was prepared at least monthly, otherwise artificial increases in the H/D exchange rate were observed. 
Figure S1. H/D Exchange for N-butylethanamide (1).

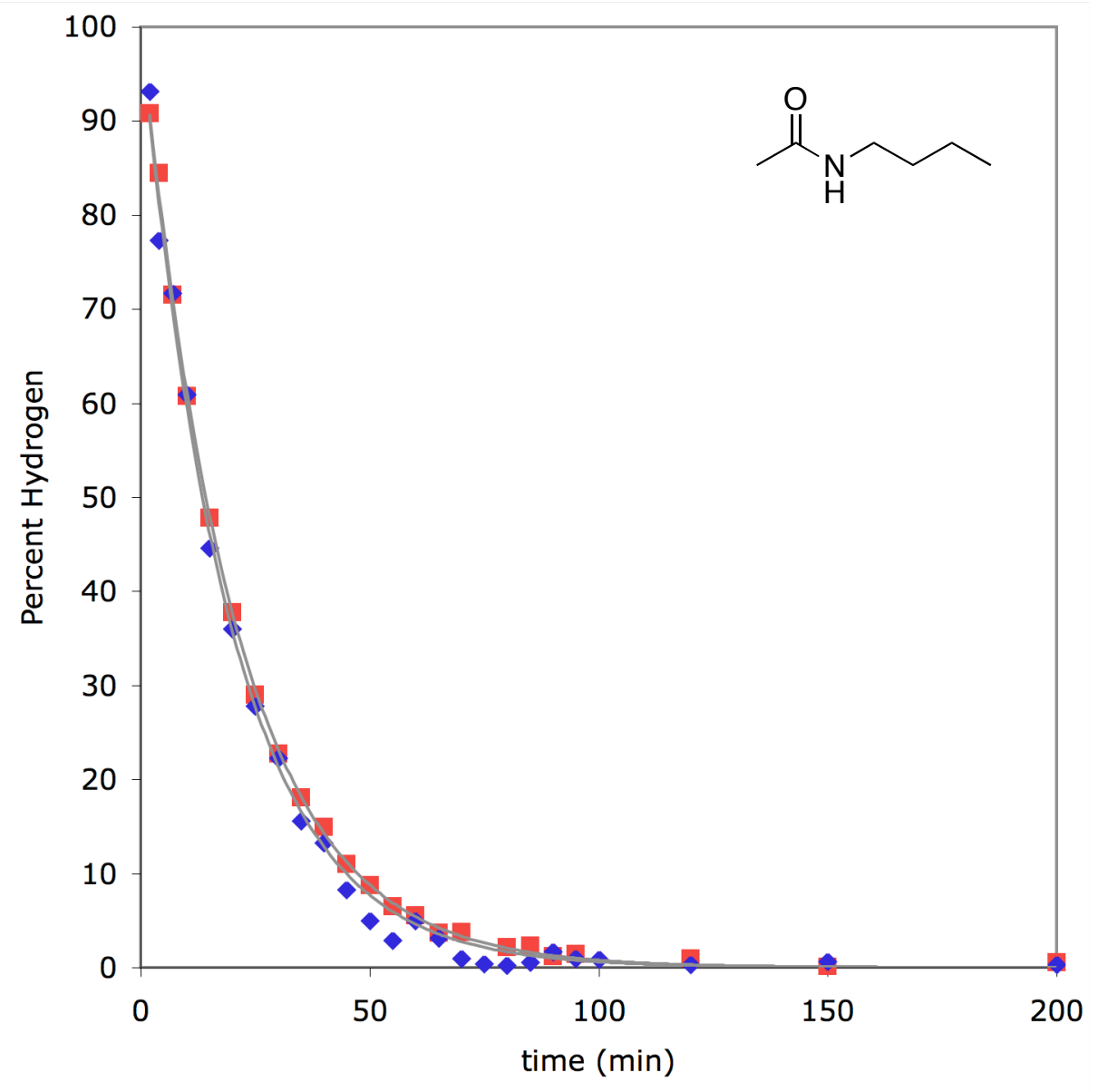

$\mathrm{k}=0.050 \pm 0.002 \mathrm{~min}^{-1}$

$\mathrm{t}_{1 / 2}=14 \pm 1 \mathrm{~min}$ 
Figure S2. H/D Exchange for $N$-butylpropanamide (2).

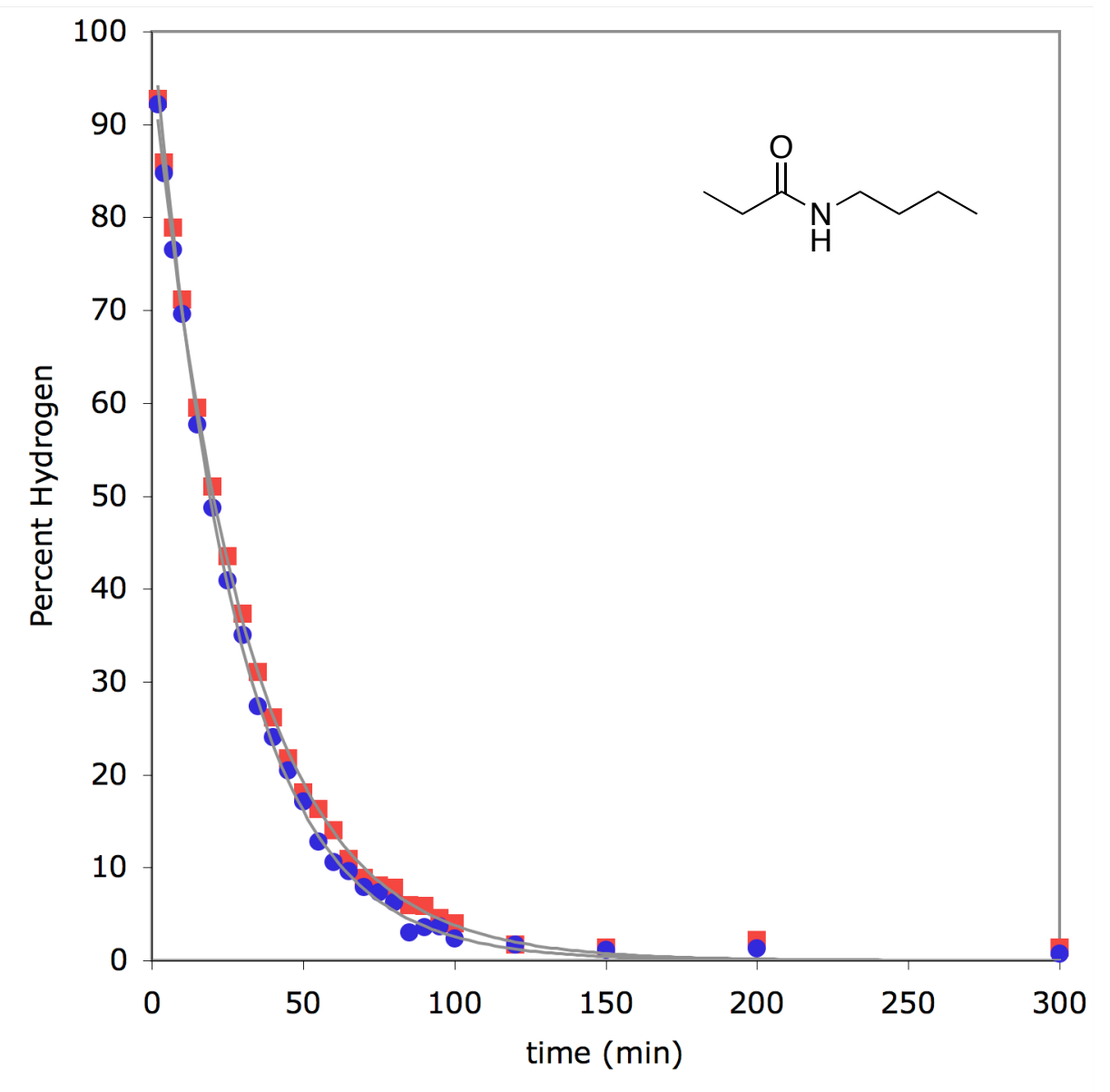

$$
\begin{aligned}
& \mathrm{k}=0.035 \pm 0.002 \mathrm{~min}^{-1} \\
& \mathrm{t}_{1 / 2}=20 \pm 1 \mathrm{~min}
\end{aligned}
$$


Figure S3. H/D Exchange for N-butyl 2-methylpropanamide (3).

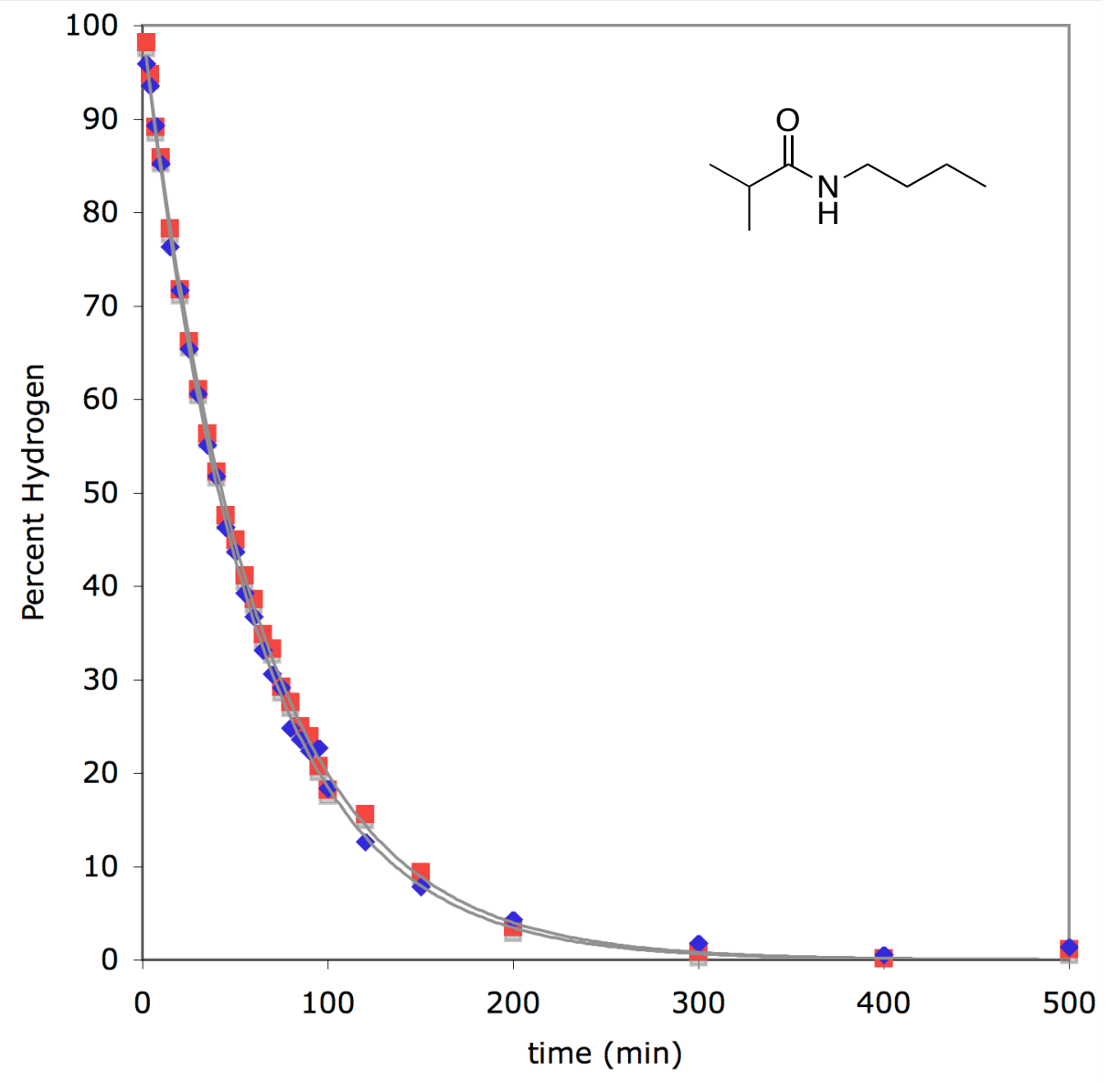

$\mathrm{k}=0.017 \pm 0.001 \mathrm{~min}^{-1}$

$\mathrm{t}_{1 / 2}=42 \pm 2 \mathrm{~min}$ 
Figure S4. H/D Exchange for $N$-butyl-2,2-dimethylpropanamide (4).

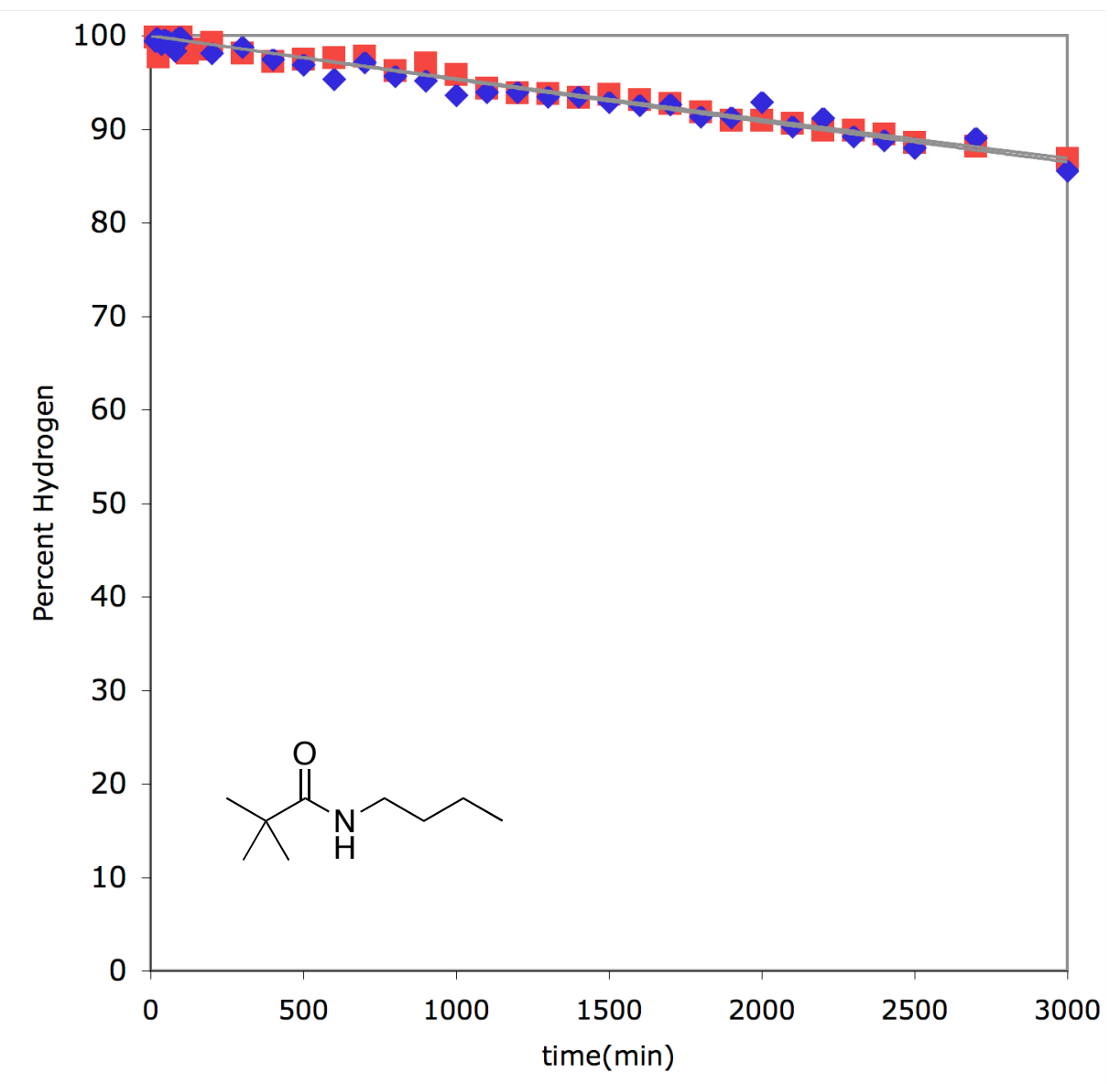

$\mathrm{k}=0.000048 \pm 0.000001 \mathrm{~min}^{-1}$

$\mathrm{t}_{1 / 2}=14500 \pm 300 \mathrm{~min}$ 
Figure S5. H/D Exchange for N-isopropylethanamide (5).

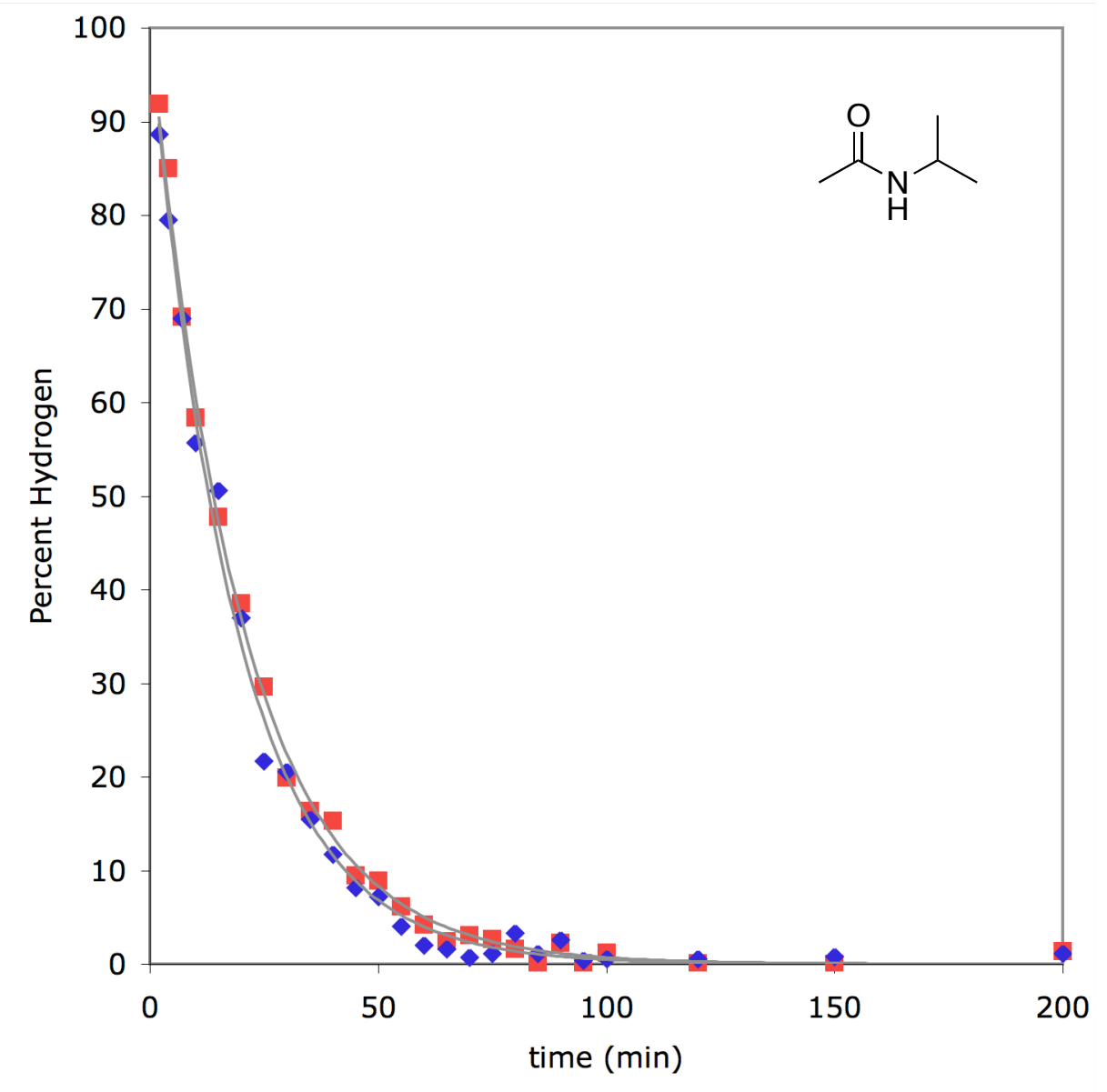

$\mathrm{k}=0.052 \pm 0.003 \mathrm{~min}^{-1}$

$\mathrm{t}_{1 / 2}=14 \pm 1 \mathrm{~min}$ 
Figure S6. H/D Exchange for $N$-tert-butylethanamide (6).

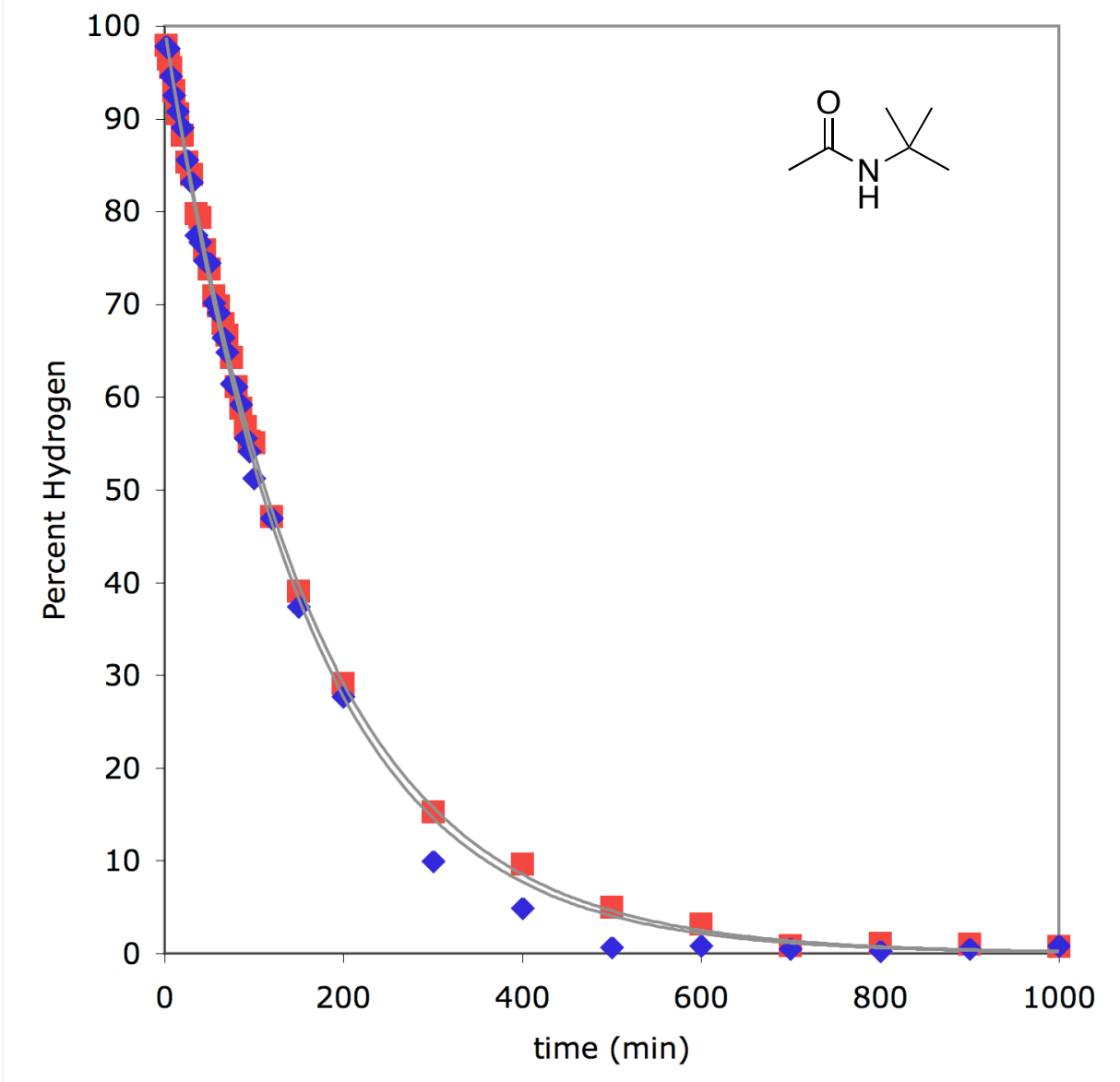

$\mathrm{k}=0.0063 \pm 0.0002 \mathrm{~min}^{-1}$

$\mathrm{t}_{1 / 2}=110 \pm 4 \mathrm{~min}$ 
Figure S7. H/D Exchange for tert-butyl butylcarbamate (7).

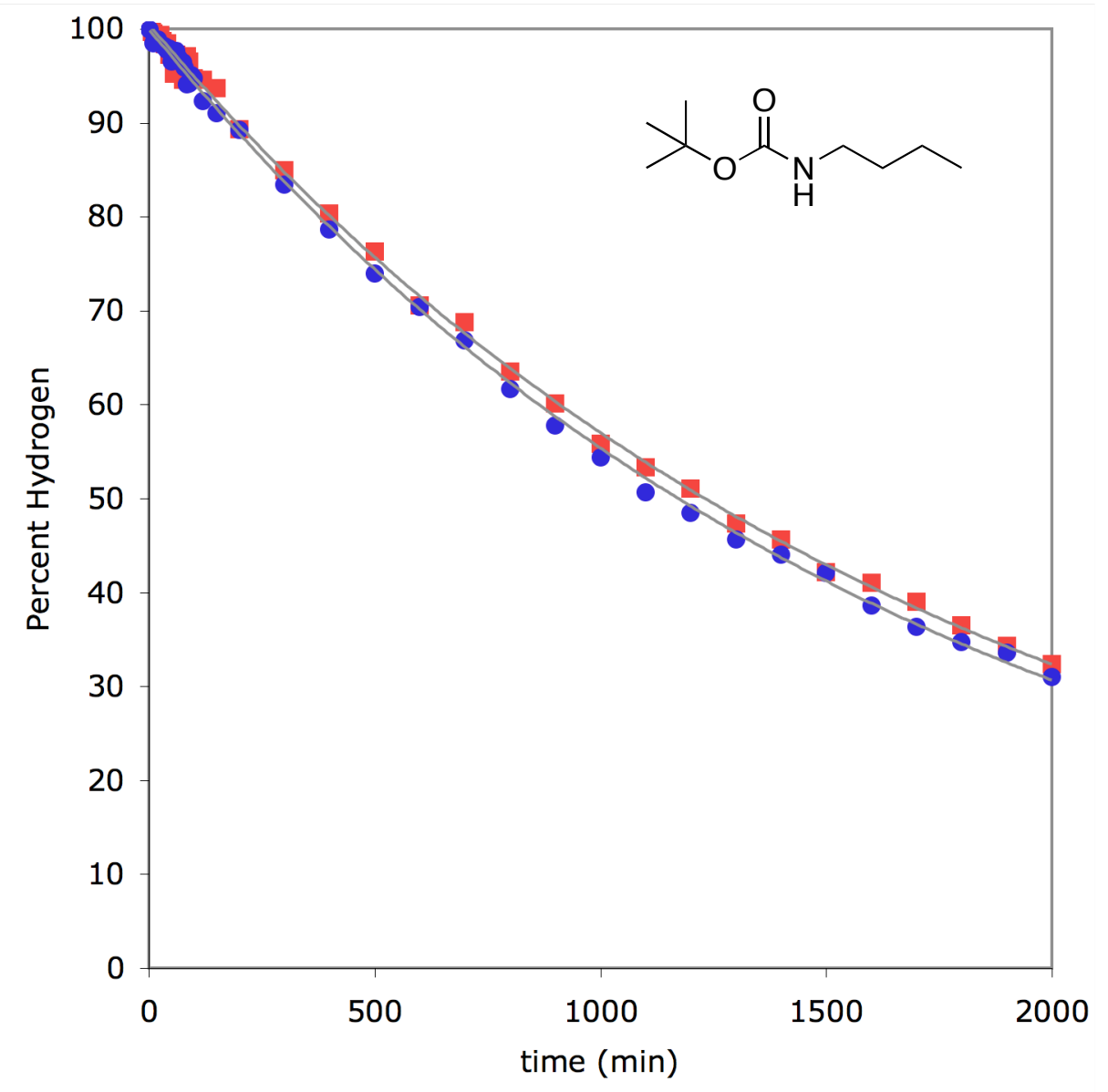

$\mathrm{k}=0.00058 \pm 0.00002 \mathrm{~min}^{-1}$

$\mathrm{t}_{1 / 2}=1200 \pm 40 \mathrm{~min}$ 
Figure S8. H/D Exchange for tert-butyl isopropylcarbamate (8).

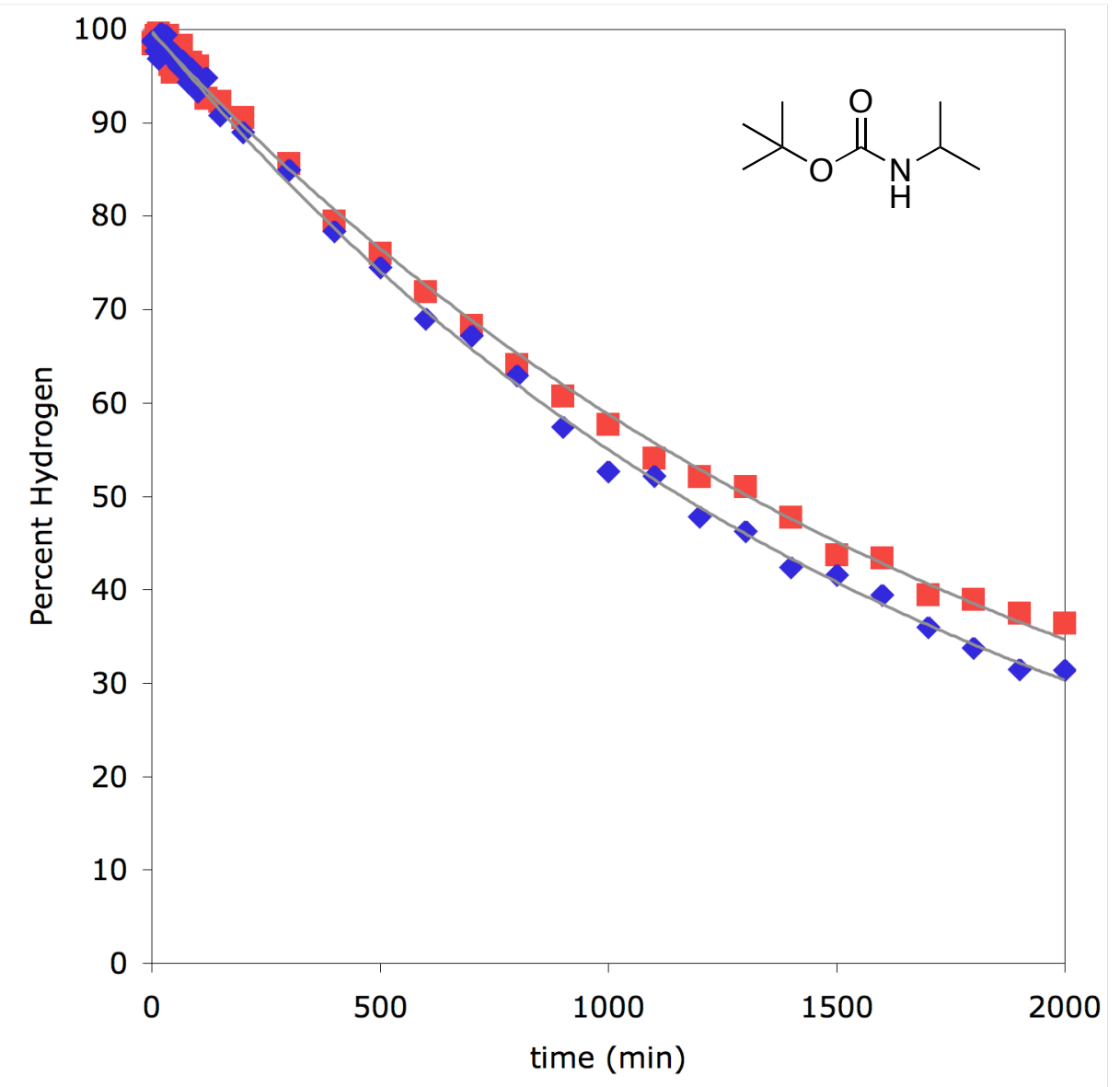

$\mathrm{k}=0.00057 \pm 0.00004 \min ^{-1}$

$\mathrm{t}_{1 / 2}=1220 \pm 90 \mathrm{~min}$ 
Figure S9. H/D Exchange for tert-butyl tert-butylcarbamate (9).

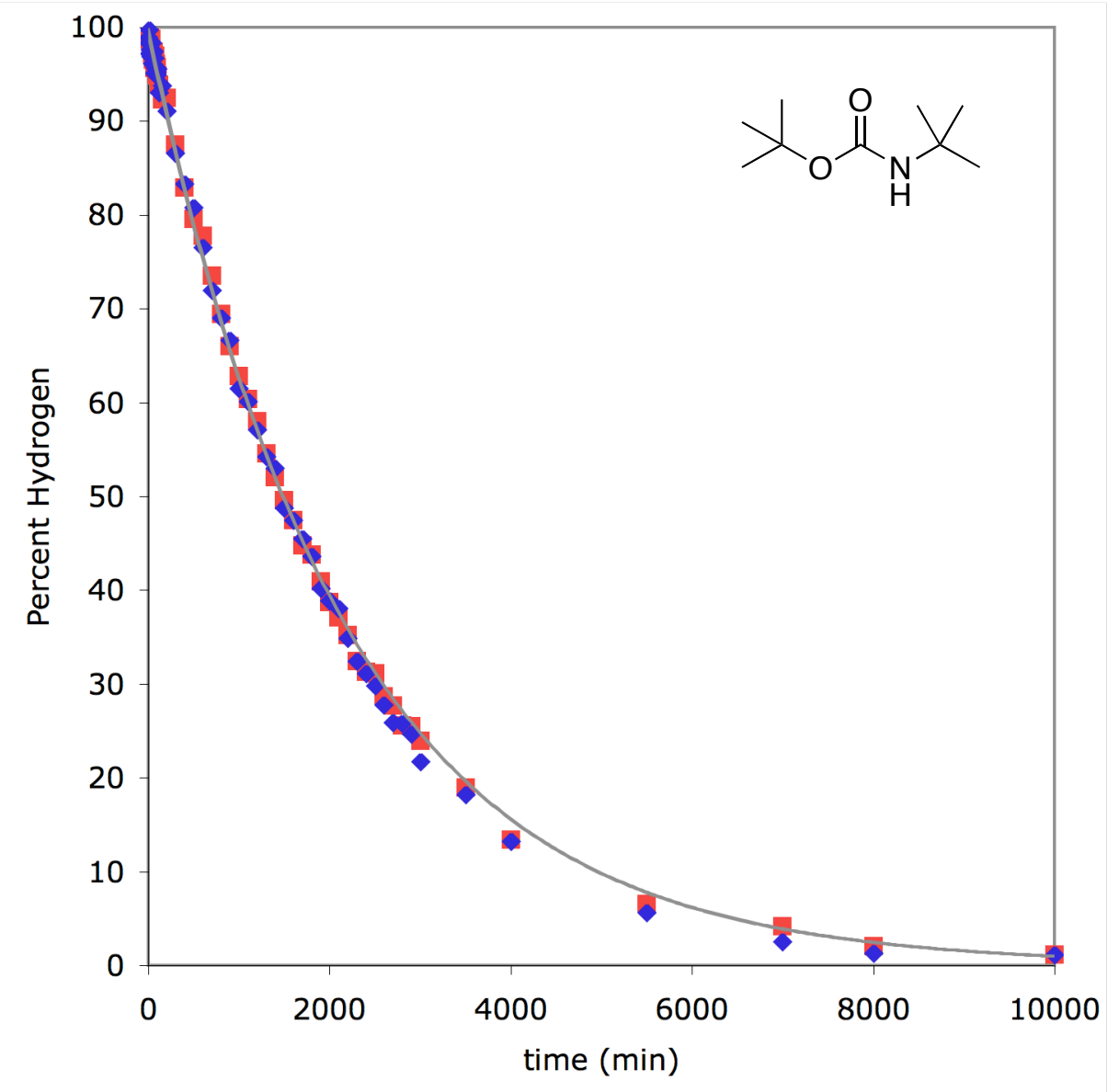

$$
\begin{aligned}
& \mathrm{k}=0.00048 \pm 0.00001 \mathrm{~min}^{-1} \\
& \mathrm{t}_{1 / 2}=1450 \pm 13 \mathrm{~min}
\end{aligned}
$$


Figure S10. H/D Exchange for N-butyl 2,2,2-trifluoroacetamide (10).

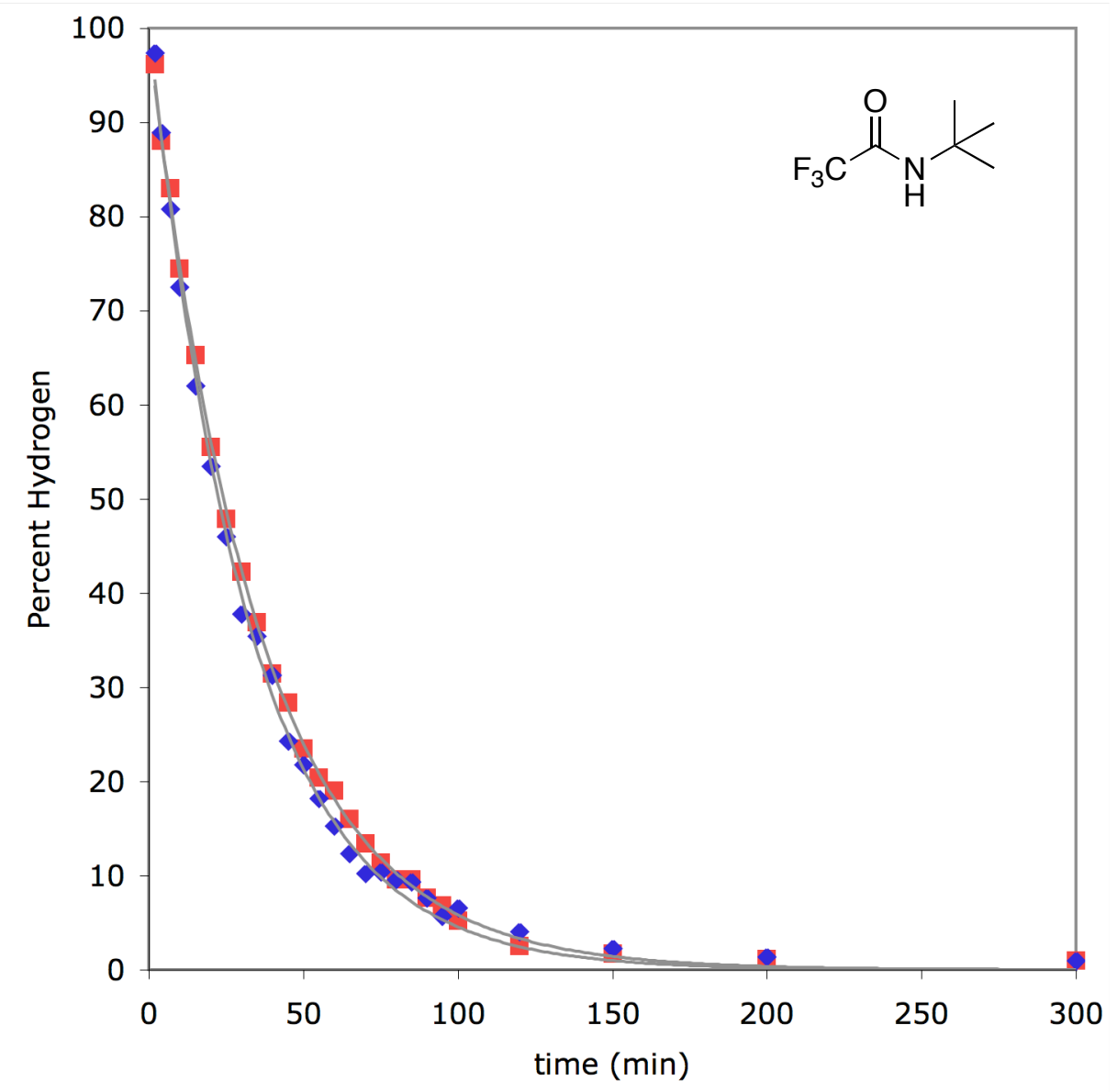

$\mathrm{k}=0.030 \pm 0.002 \mathrm{~min}^{-1}$

$\mathrm{t}_{1 / 2}=24 \pm 1 \mathrm{~min}$ 
Figure S11. Comparative H/D Exchange for all non-hydrogen bonding controls (1-10). Amides are blue, carbamates are red and trifluoroacetamide is green,. Closed symbols indicate differing nitrogen substituents and open symbols indicate changes in the carbonyl substituent. $1 \bullet, 2 \bigcirc, 3 \diamond, 4 \square, 5 \diamond, 6 \square, 7 \bullet, 8 \diamond, 9 \square, 10 \square$. The curves for 1,5 and 7-8 are nearly coincidental, and therefore unavoidably difficult to distinguish.

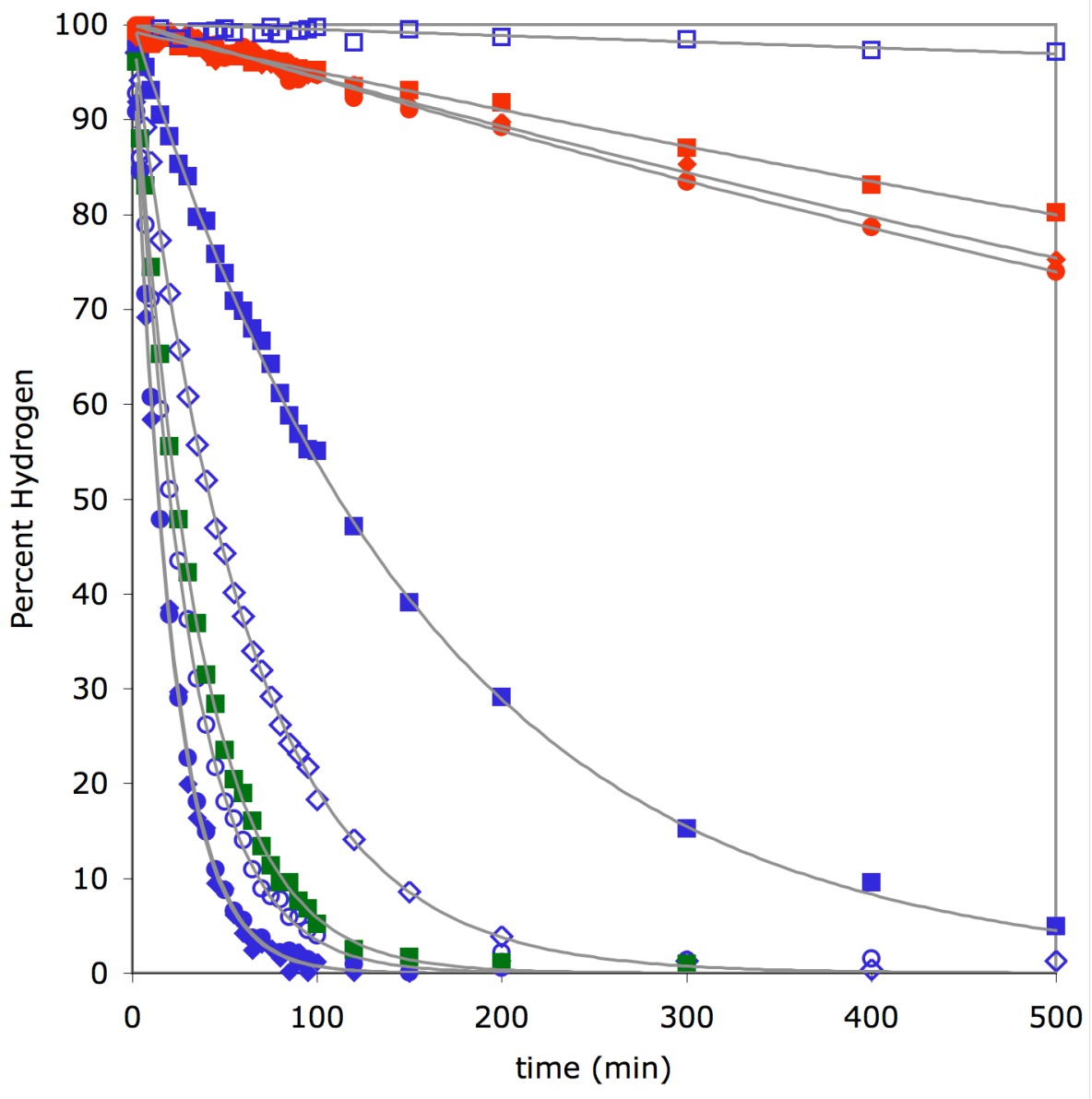


Figure S12. H/D Exchange for Boc-Gly-NHBu (11). There are three experiments shown $(\square, \times$, and $\mathrm{O})$. Blue curves are butylamide $\mathrm{NH}$ and red curves are Boc-NH.

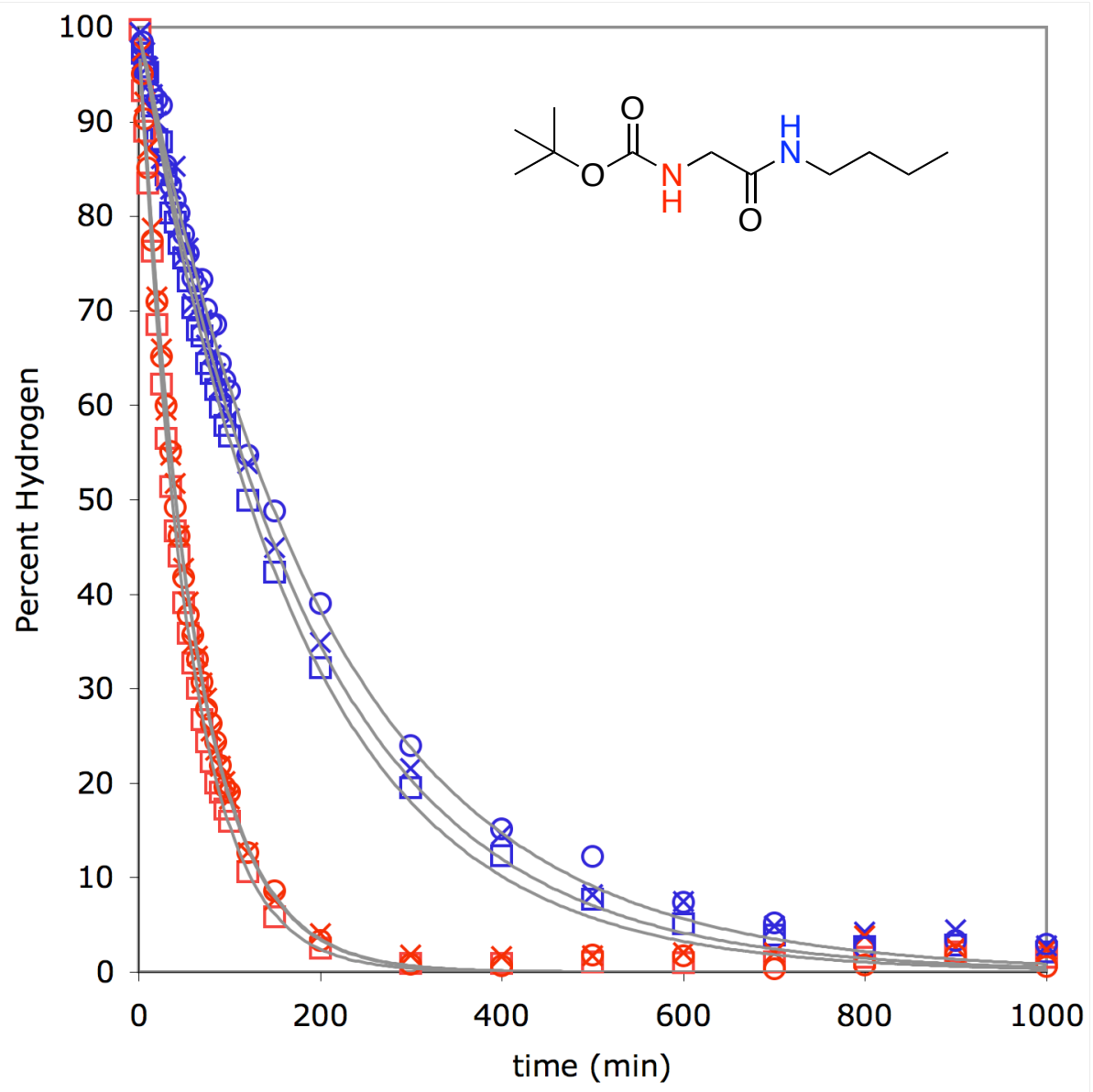

butyl amide

$\mathrm{k}=0.0053 \pm 0.0005 \mathrm{~min}^{-1}$

$\mathrm{t}_{1 / 2}=132 \pm 12 \mathrm{~min}$

t-butoxy carbamate

$\mathrm{k}=0.017 \pm 0.001 \mathrm{~min}^{-1}$

$\mathrm{t}_{1 / 2}=40 \pm 3 \mathrm{~min}$ 
Figure S13. H/D Exchange for Boc-NMe-Gly-NHBu (12).

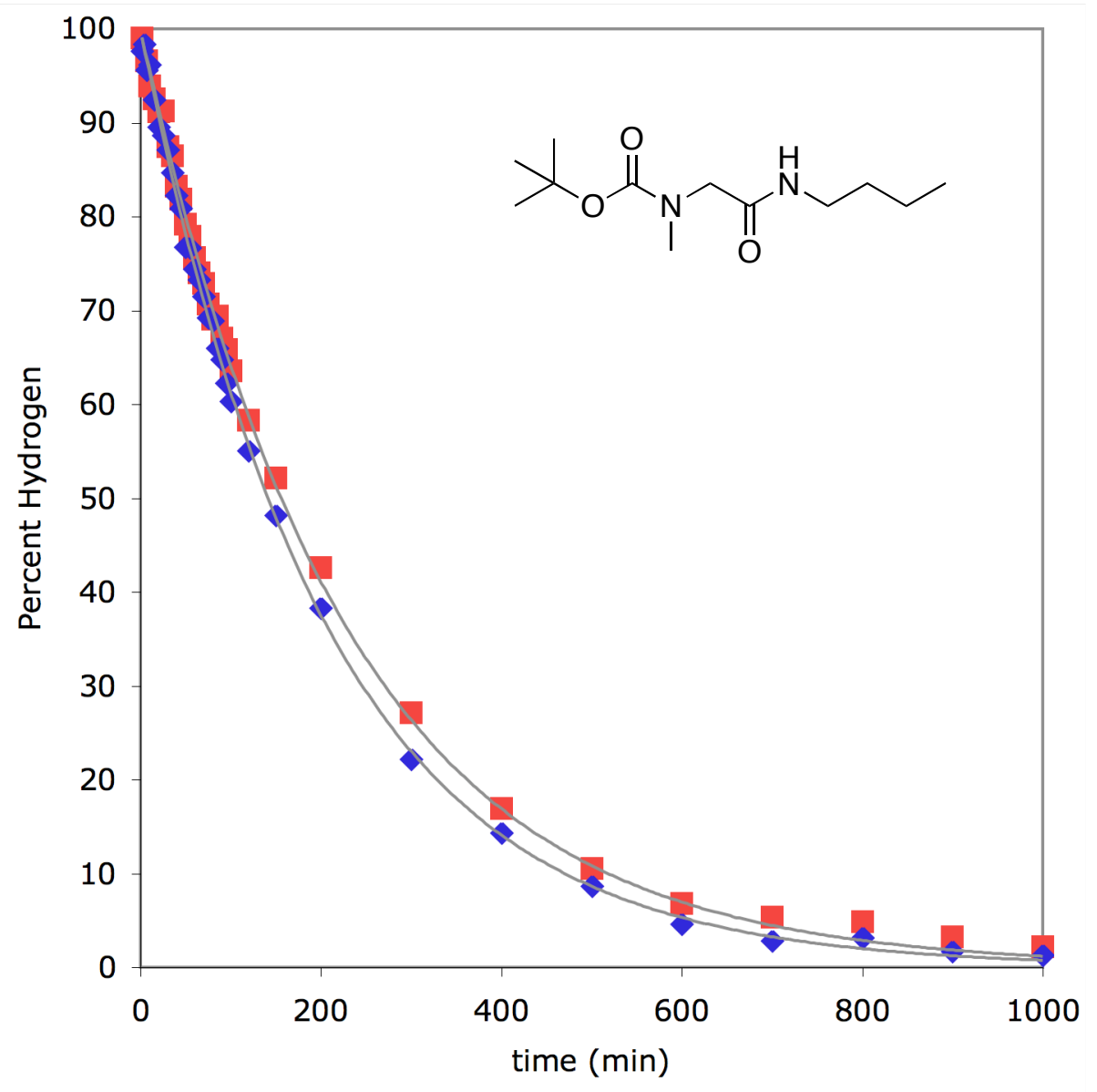

$\mathrm{k}=0.0047 \pm 0.0003 \mathrm{~min}^{-1}$

$\mathrm{t}_{1 / 2}=150 \pm 10 \mathrm{~min}$ 
Figure S14. H/D Exchange for Boc-Gly-NMe 2 (13).

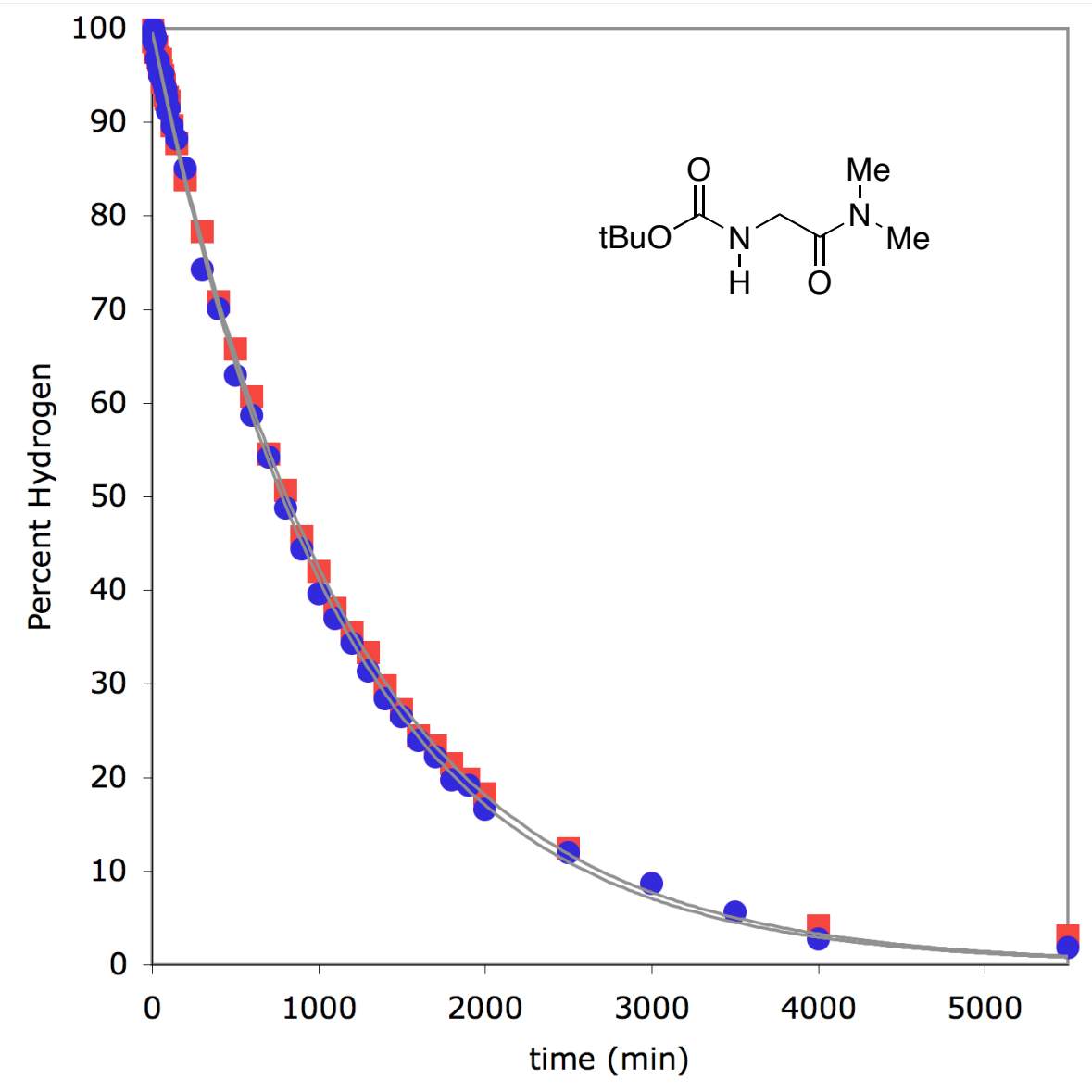

$$
\begin{aligned}
& \mathrm{k}=0.00087 \pm 0.00002 \mathrm{~min}^{-1} \\
& \mathrm{t}_{1 / 2}=800 \pm 20 \mathrm{~min}
\end{aligned}
$$


Figure S15. H/D Exchange for Boc-NH- $\mathrm{CH}_{2} \mathrm{CH}_{2}-\mathrm{NH}-\mathrm{Ac}$ (14). There are two experiments shown $(\square$, and $O)$. Blue curves are the acetamide $\mathrm{NH}$, red curves are Boc$\mathrm{NH}$. For comparison, curves are provided for N-butyl propanamide $(\mathbf{4},+)$ and for tertbutyl butylcarbamate $(7, \times)$.

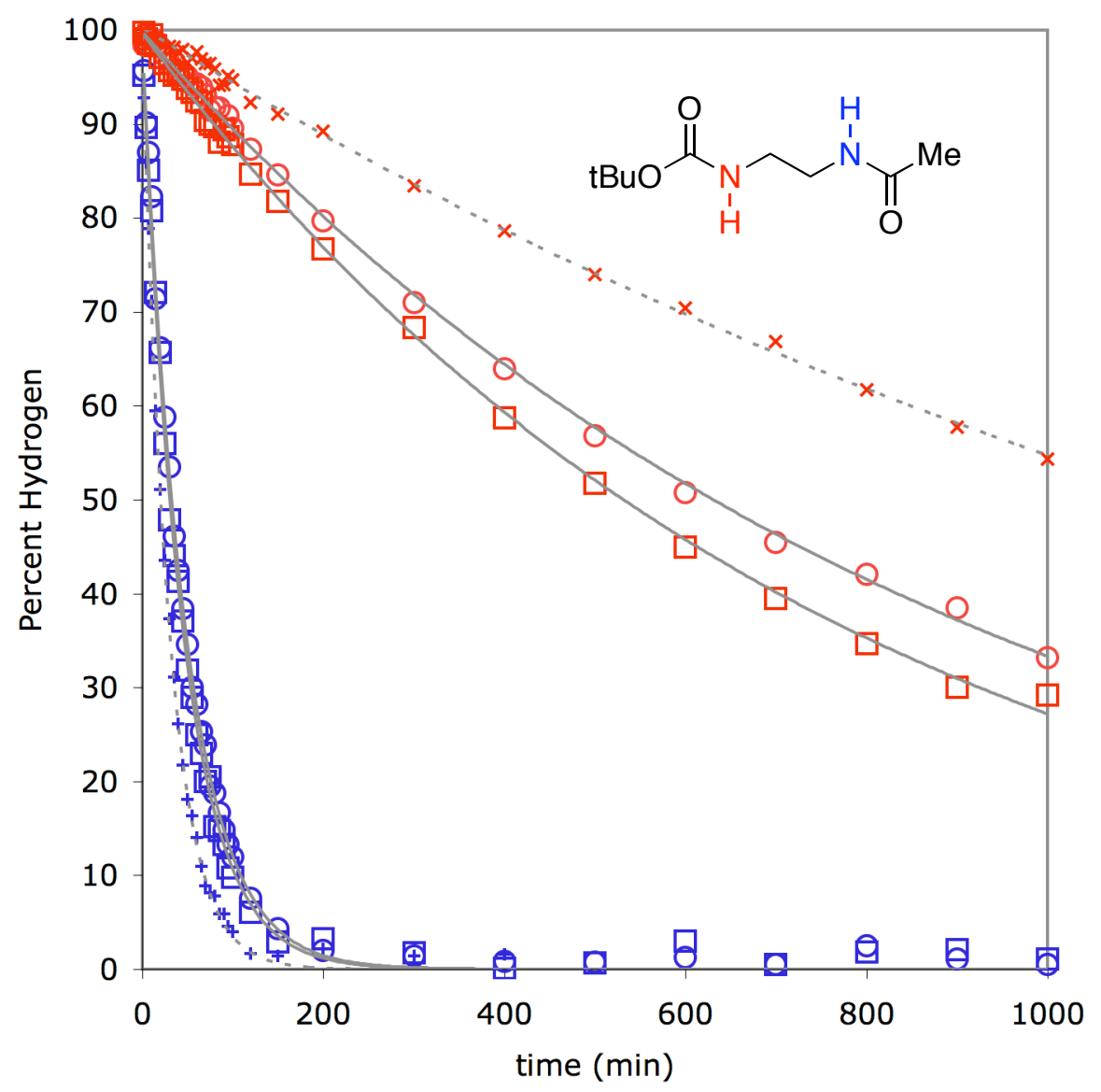

acetamide

$\mathrm{k}=0.0212 \pm 0.0002 \mathrm{~min}^{-1}$

$\mathrm{t}_{1 / 2}=33 \pm 1 \mathrm{~min}$

carbamate

$\mathrm{k}=0.00122 \pm 0.00015 \mathrm{~min}^{-1}$

$\mathrm{t}_{1 / 2}=570 \pm 70 \mathrm{~min}$ 
Figure S16. H/D Exchange for Boc-Gly-Gly-NHBu (15). There are two experiments shown $(\square$, and $\mathrm{O})$. Blue curves are butylamide $\mathrm{NH}$, red curves are Boc-NH, and green curves are the central amide.

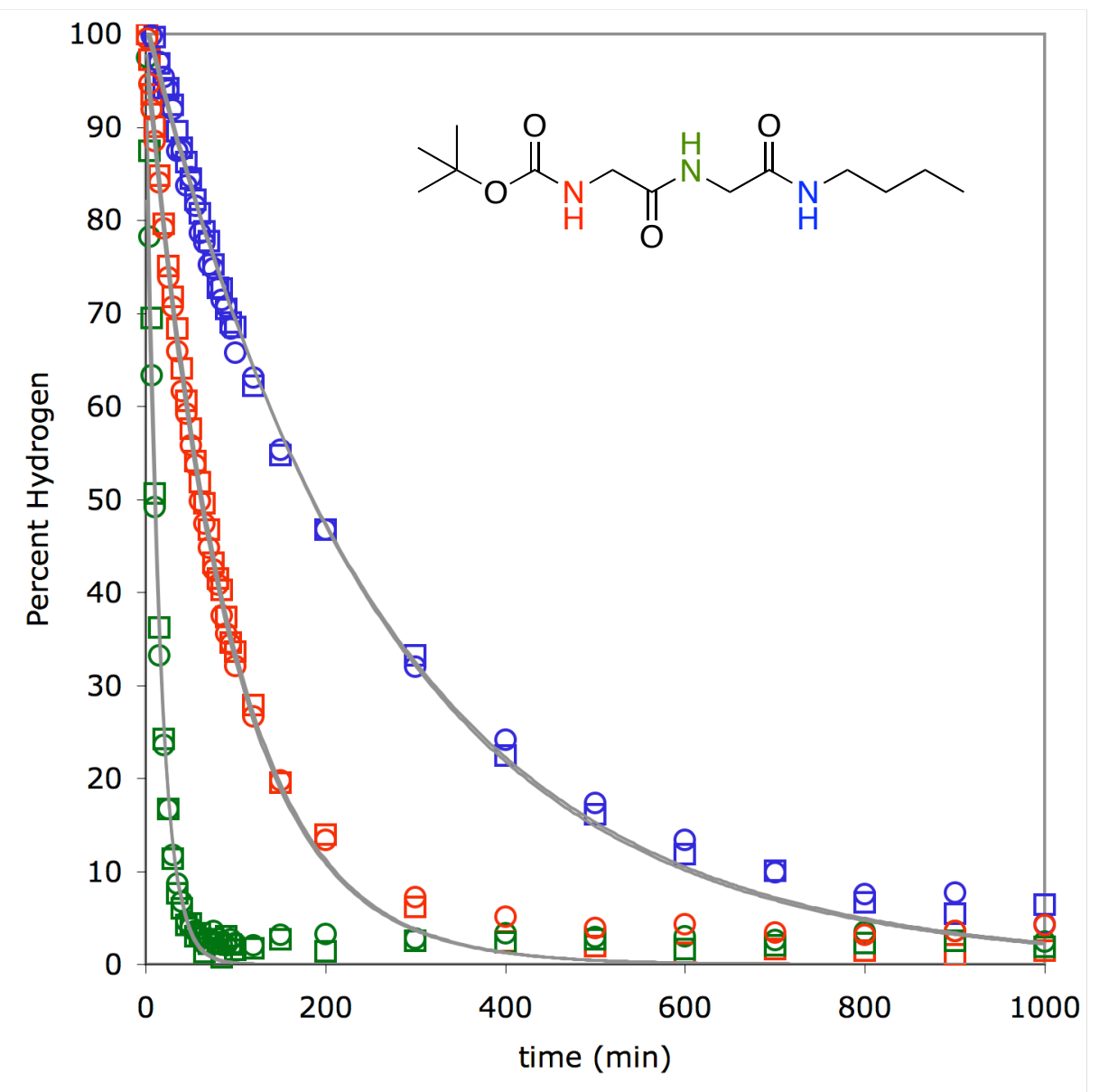

butyl amide

$\mathrm{k}=0.0039 \pm 0.0001 \mathrm{~min}^{-1}$

$\mathrm{t}_{1 / 2}=180 \pm 2 \mathrm{~min}$

carbamate

$\mathrm{k}=0.011 \pm 0.001 \mathrm{~min}^{-1}$

$\mathrm{t}_{1 / 2}=63 \pm 1 \mathrm{~min}$

central amide

$\mathrm{k}=0.056 \pm 0.013 \mathrm{~min}^{-1}$

$\mathrm{t}_{1 / 2}=13 \pm 3 \mathrm{~min}$ 
Figure S17. H/D Exchange for Boc-Gly-Gly-NHBu (15). The solid symbols indicate the three N-H protons of 15: the butylamide $(\mathbf{O})$, the Boc-NH $(\square)$ and the central amide $(\mathbf{\Delta})$. The open symbols indicate controls $4(O)$ and $7(\square)$. Arrows indicate the differences between non-hydrogen-bonding controls and similar hydrogen-bonding groups.

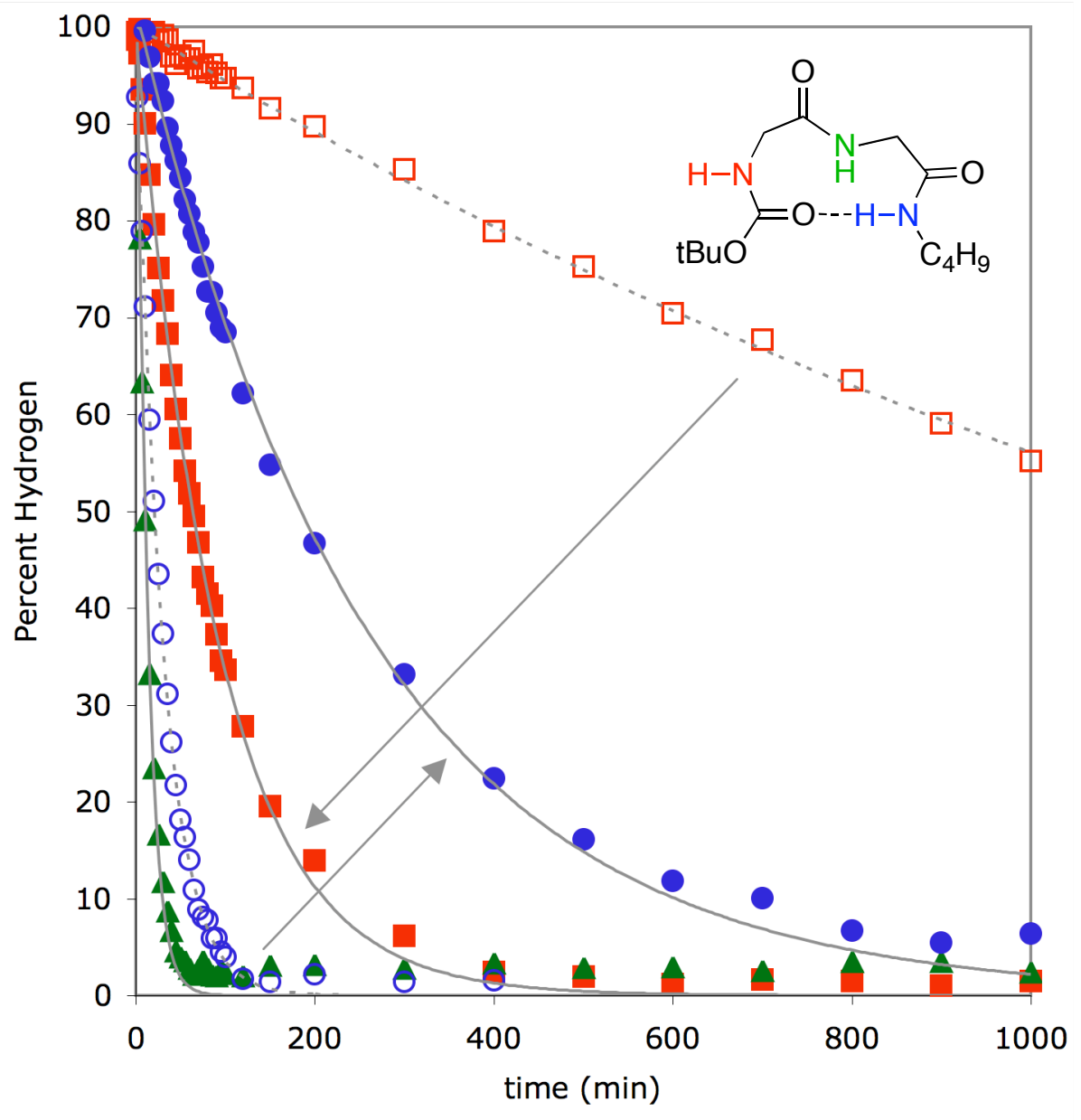


Figure S18. Solvent effect titration for Boc-Gly-NHBu (11) showing the change in chemical shift at various percentages of DMSO- $\mathrm{d}_{6}$ in $\mathrm{C}_{6} \mathrm{D}_{6}$. The two curves indicate the butylamide (O) and the Boc-NH ( $\square)$.

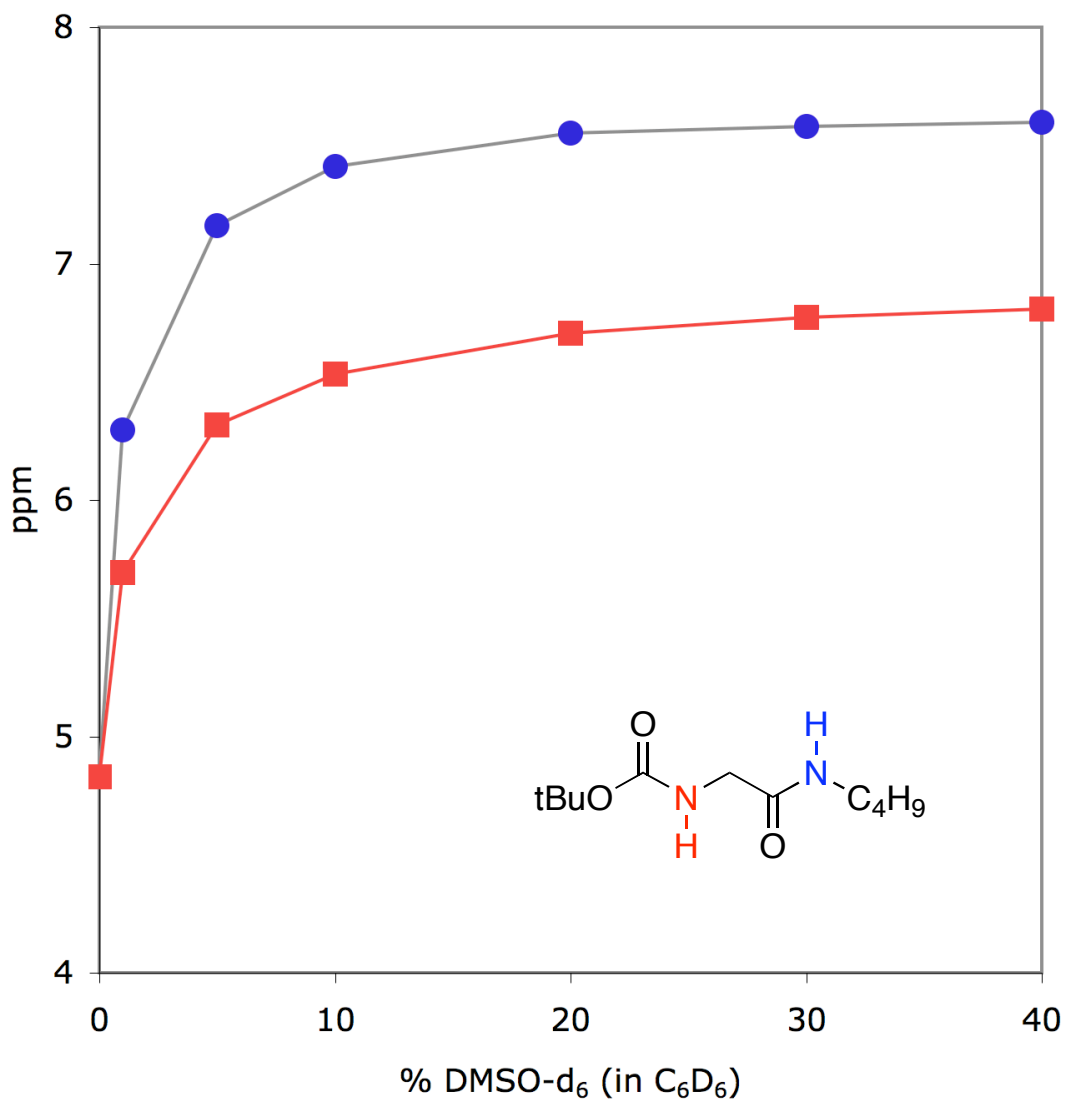


Figure S19. Infrared spectra for; a) Boc-Gly-NHBu (11), b) Boc-N-Me-Gly-NHBu (12), c) Boc-Gly-NMe 2 (13).

a)

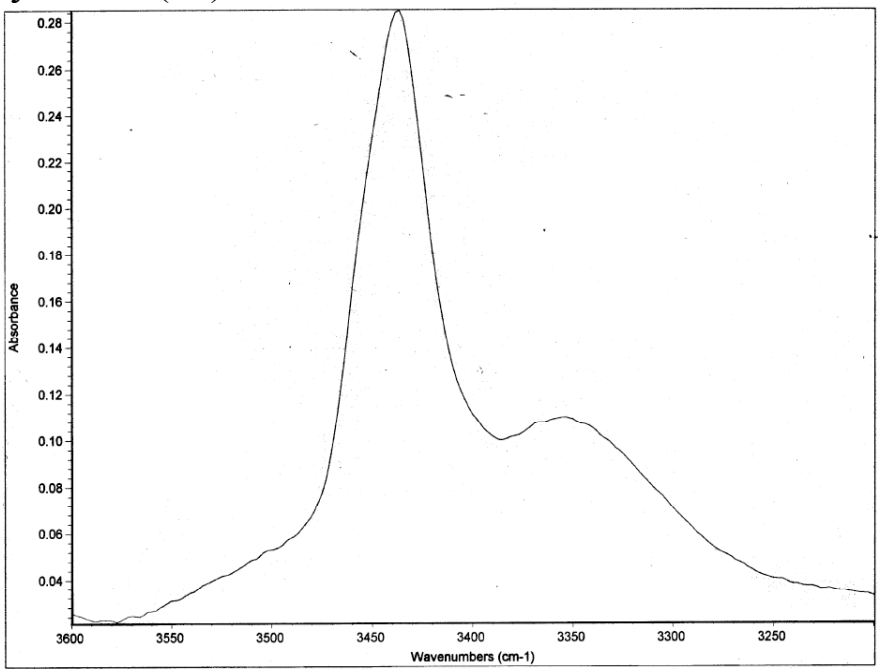<smiles>CCCCCCCCCCCCNC(=O)OC(C)(C)C</smiles>

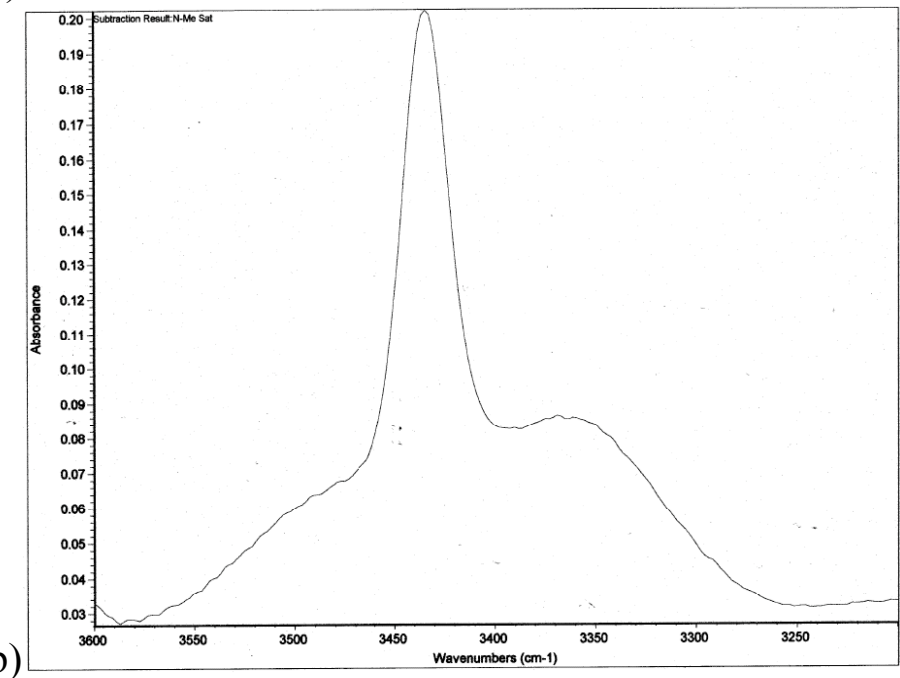

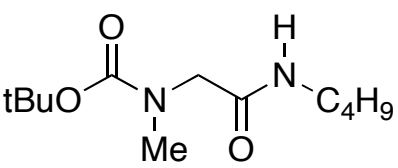

b)

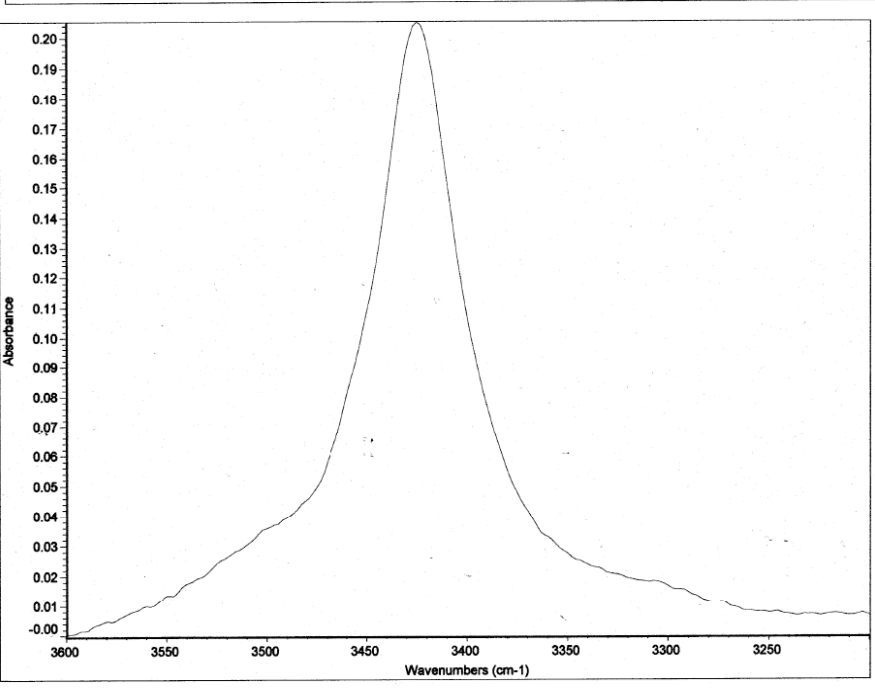<smiles>CCCCOC(=O)NCC(=O)N(C)C</smiles>

c) 

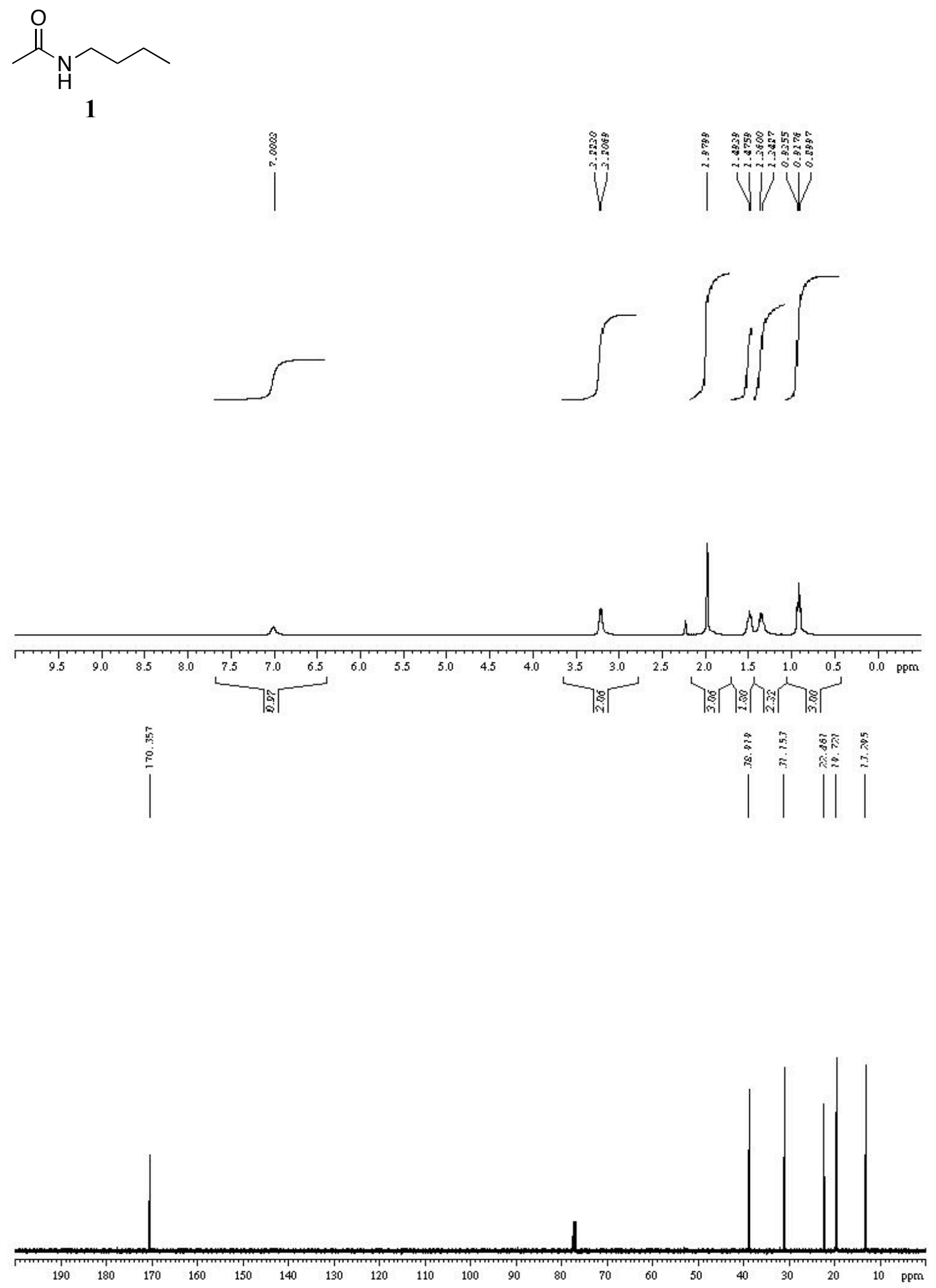
<smiles>CCCCNC(=O)CC</smiles>
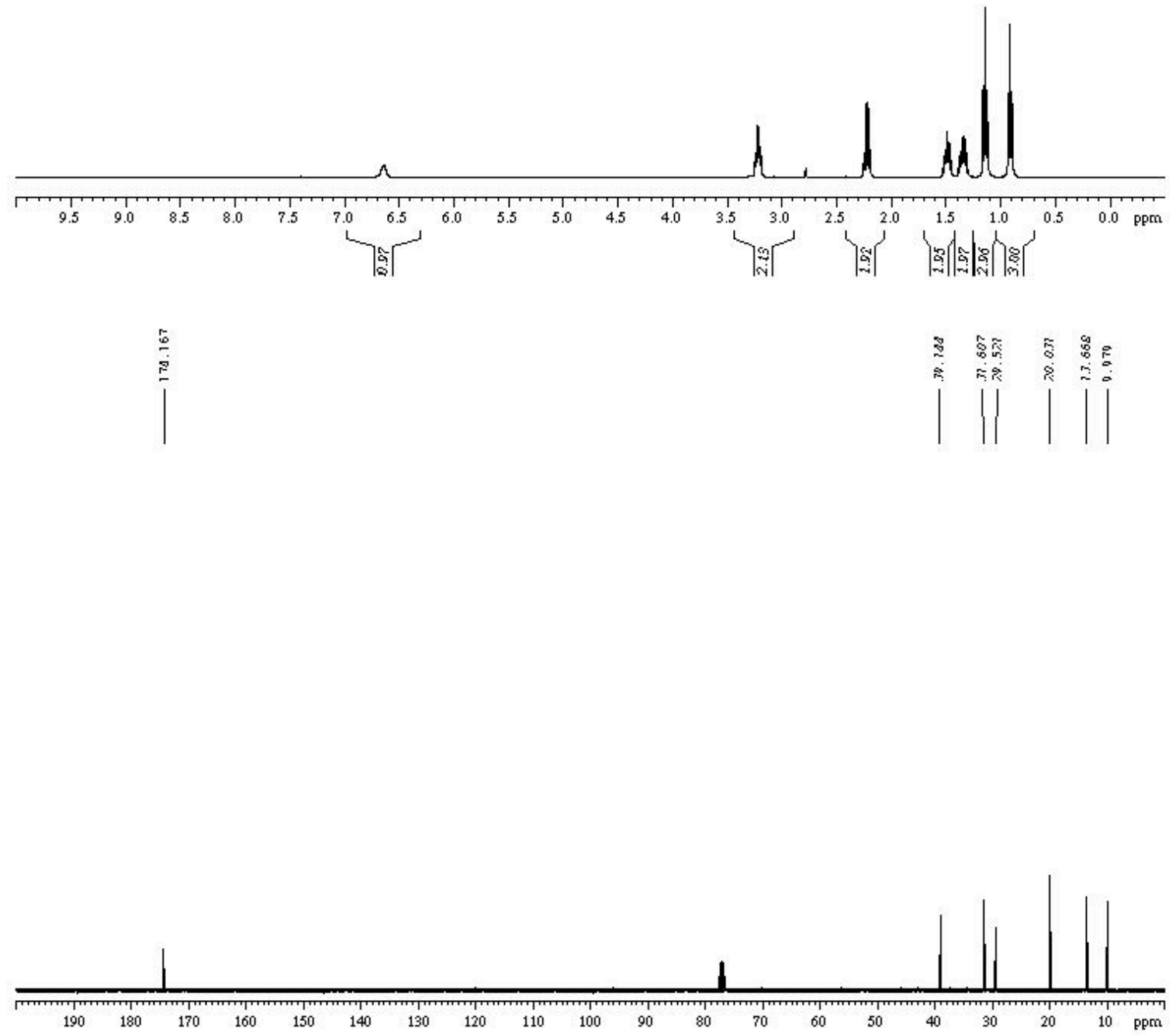
<smiles>CCCCNC(=O)C(C)C</smiles>

3
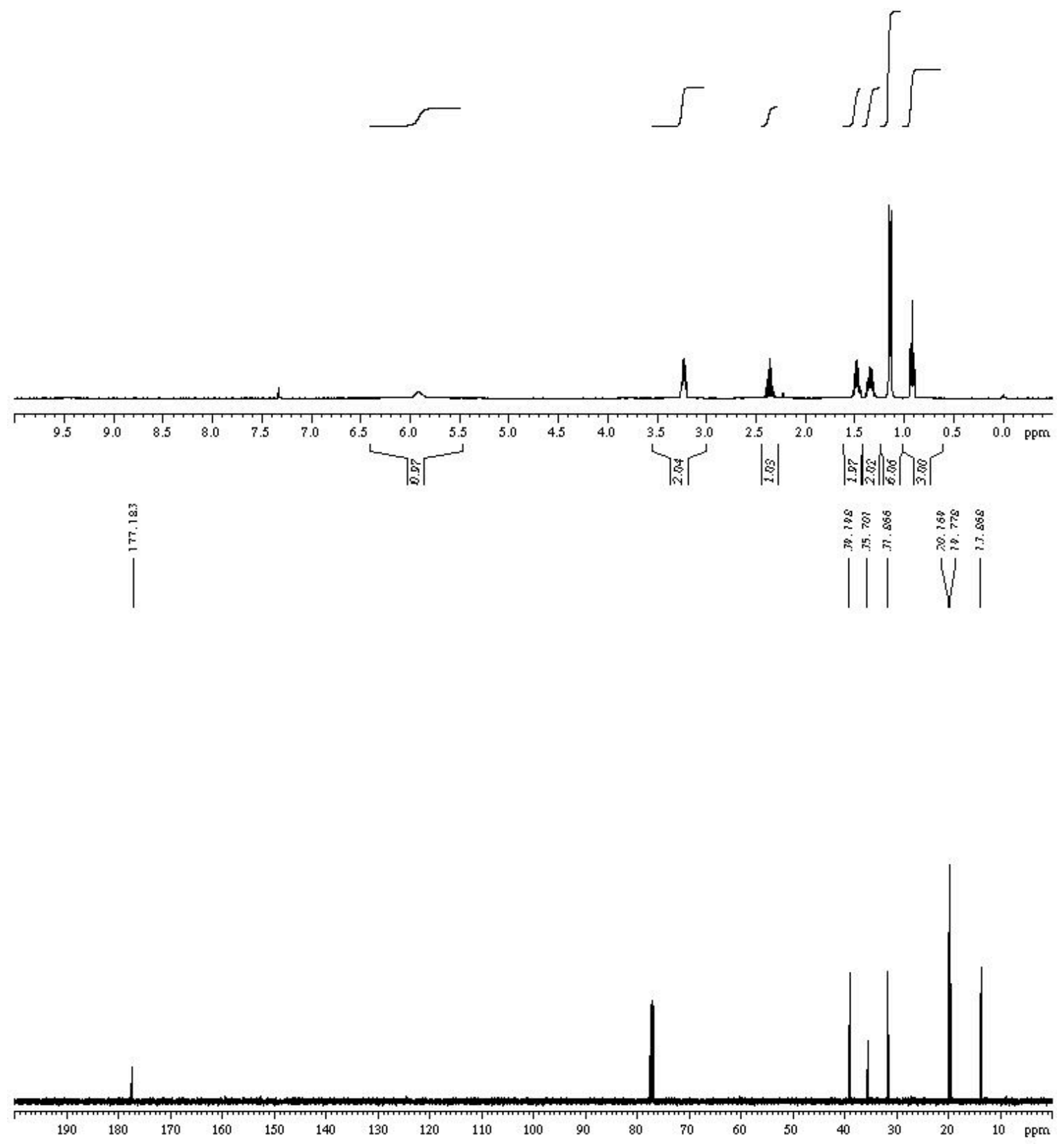
<smiles>CCCCNC(=O)C(C)(C)C</smiles>
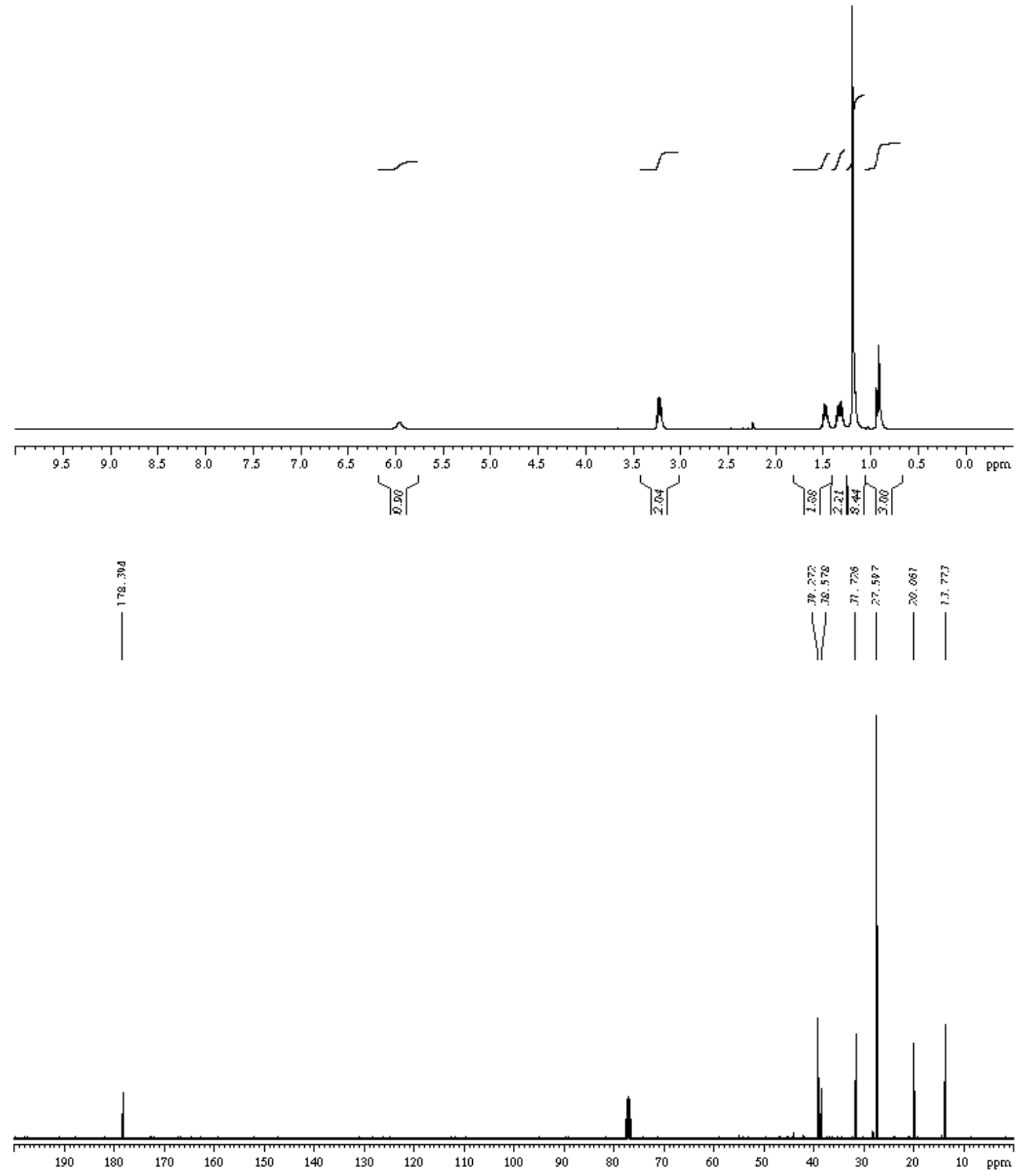
<smiles>CC(=O)NC(C)C</smiles>
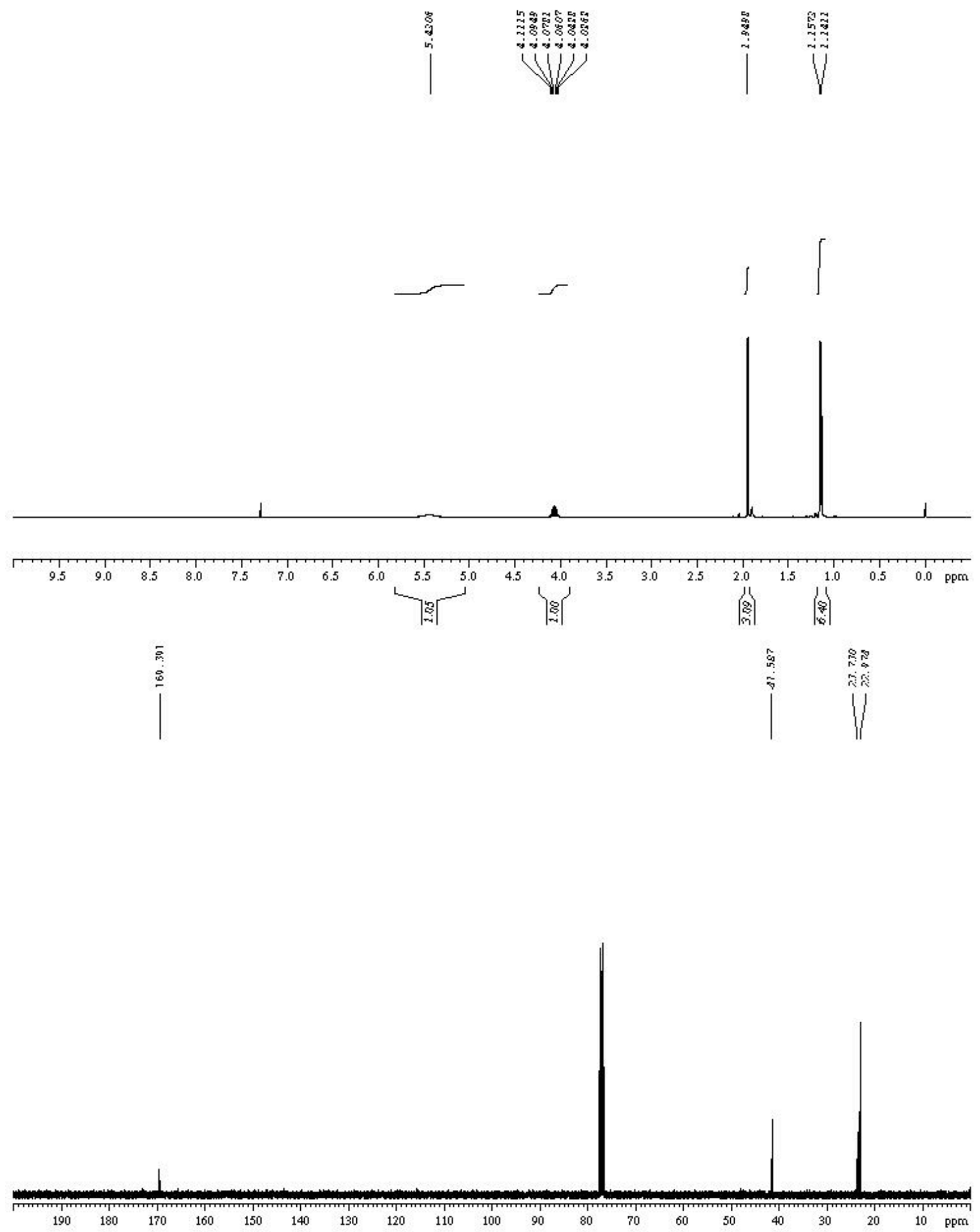

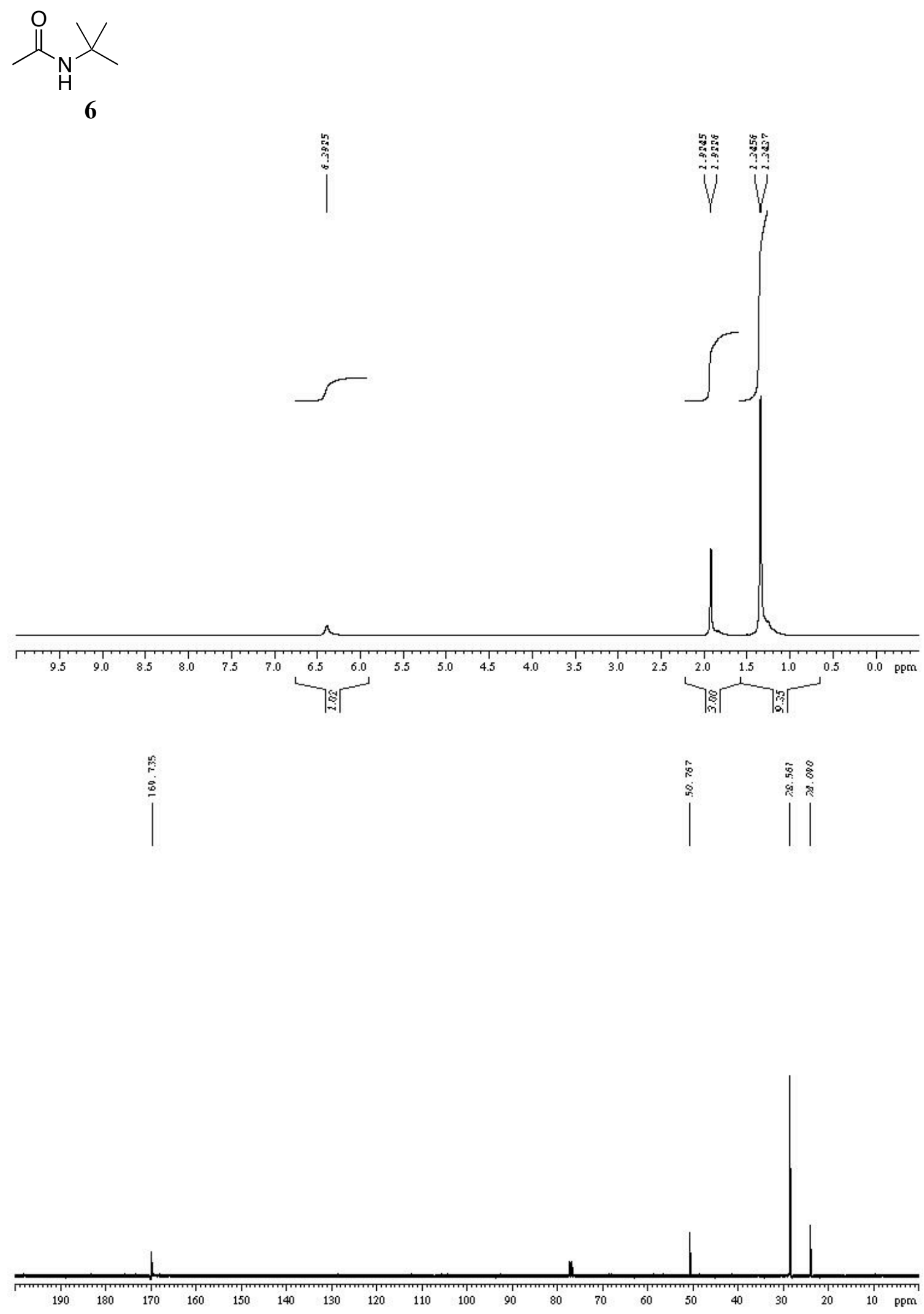

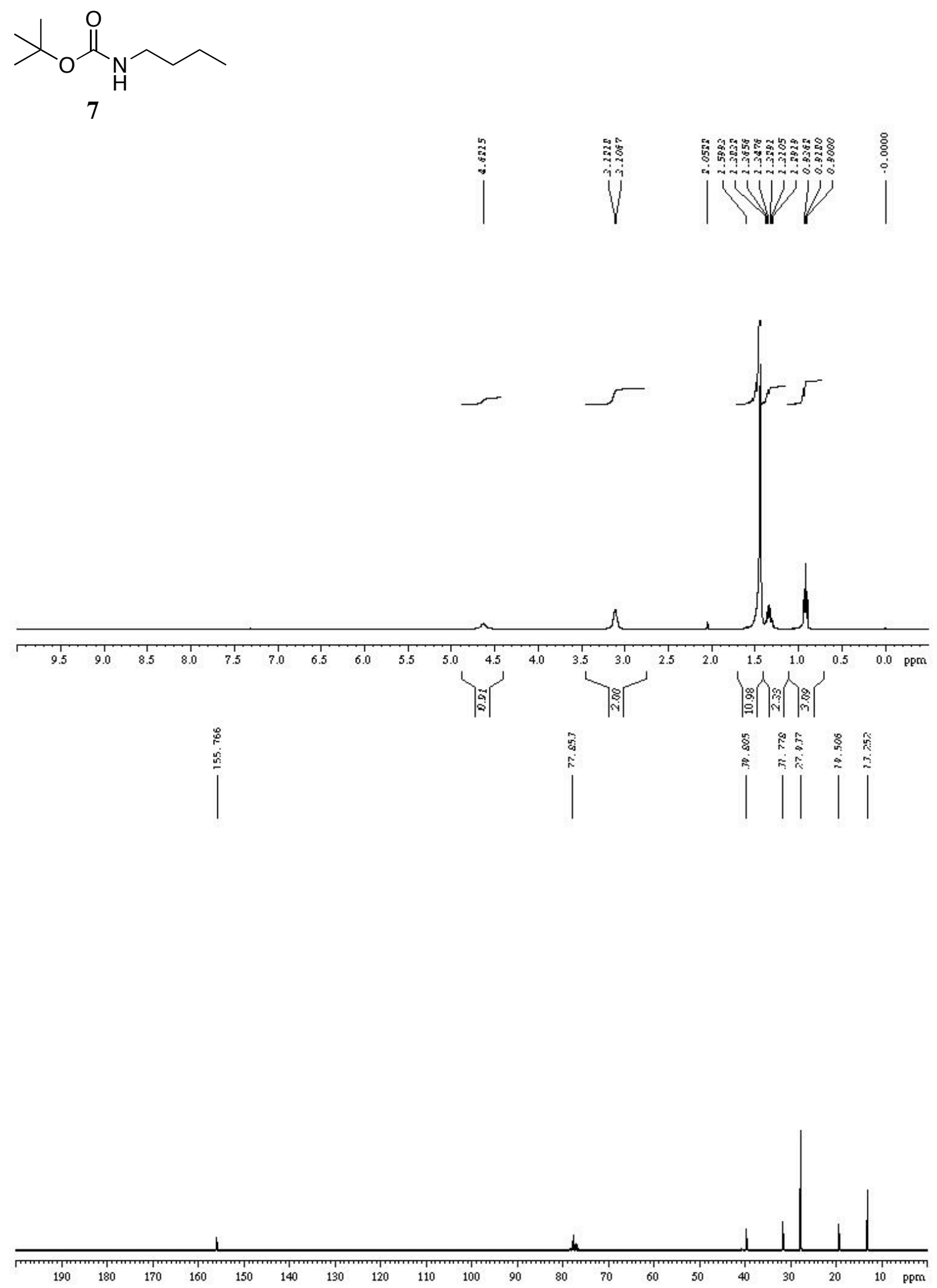

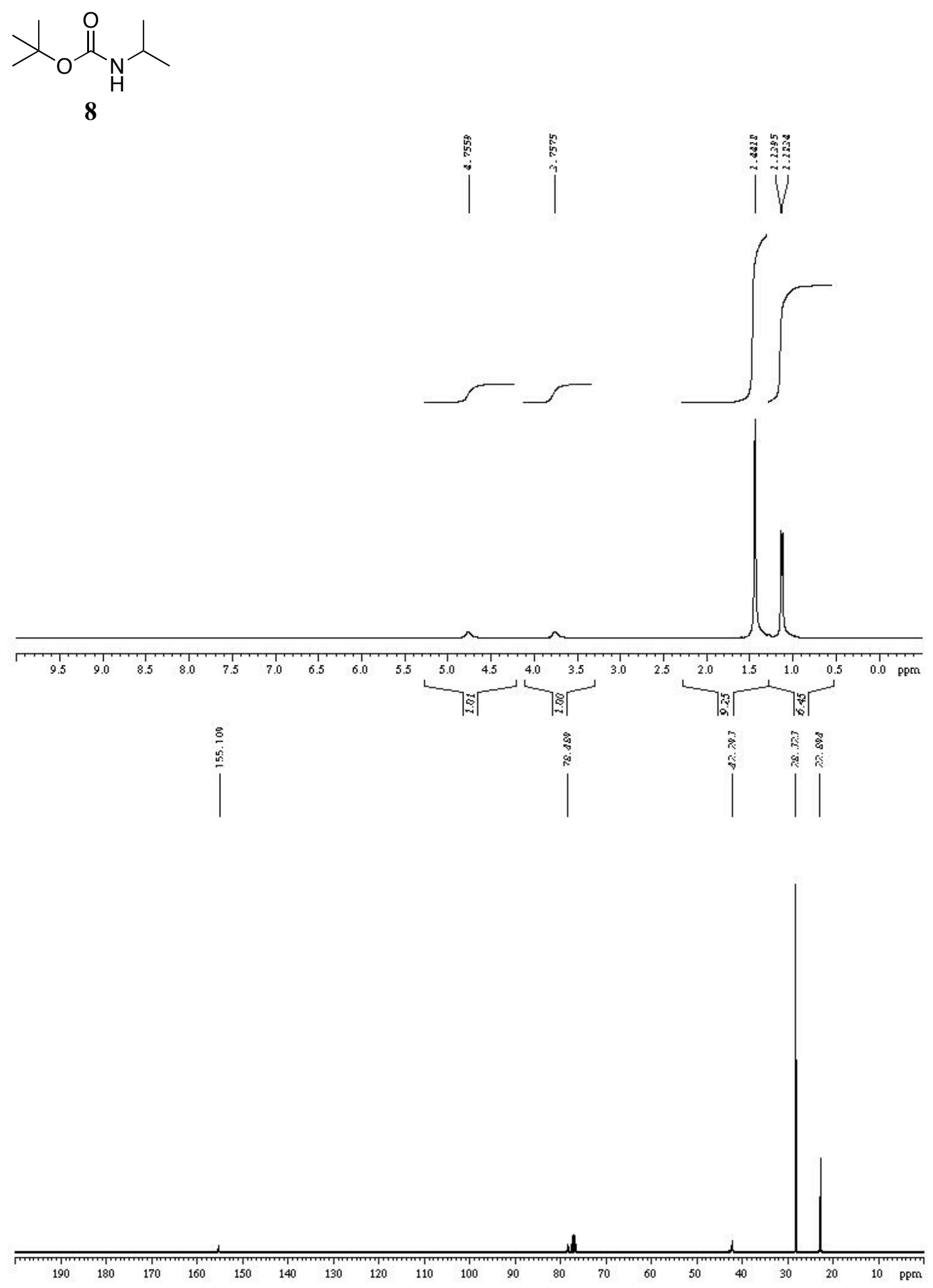
$>_{0}{ }_{n}^{O} X$

9 $\mid$

稀

$\mid$

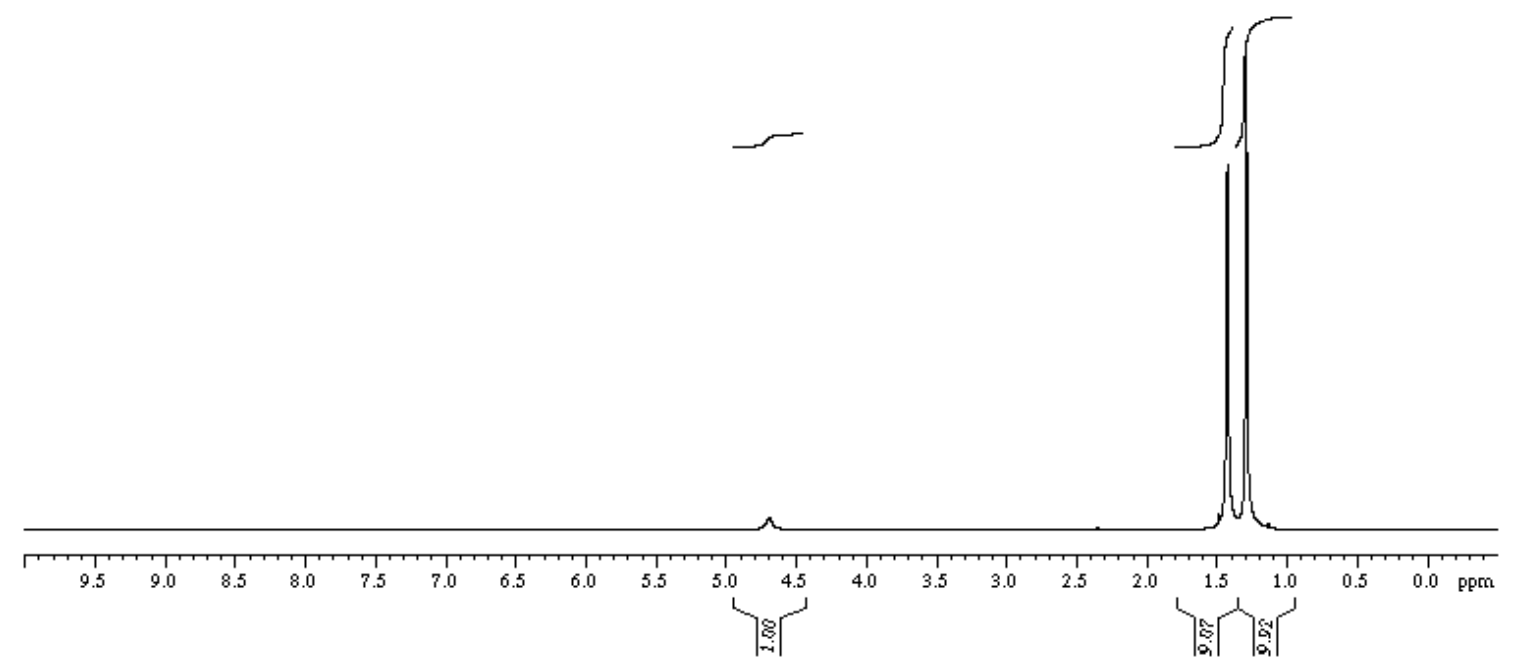


$\mathrm{F}_{3} \mathrm{C} \underset{\mathrm{H}}{\stackrel{\mathrm{O}}{\mathrm{O}}<}$

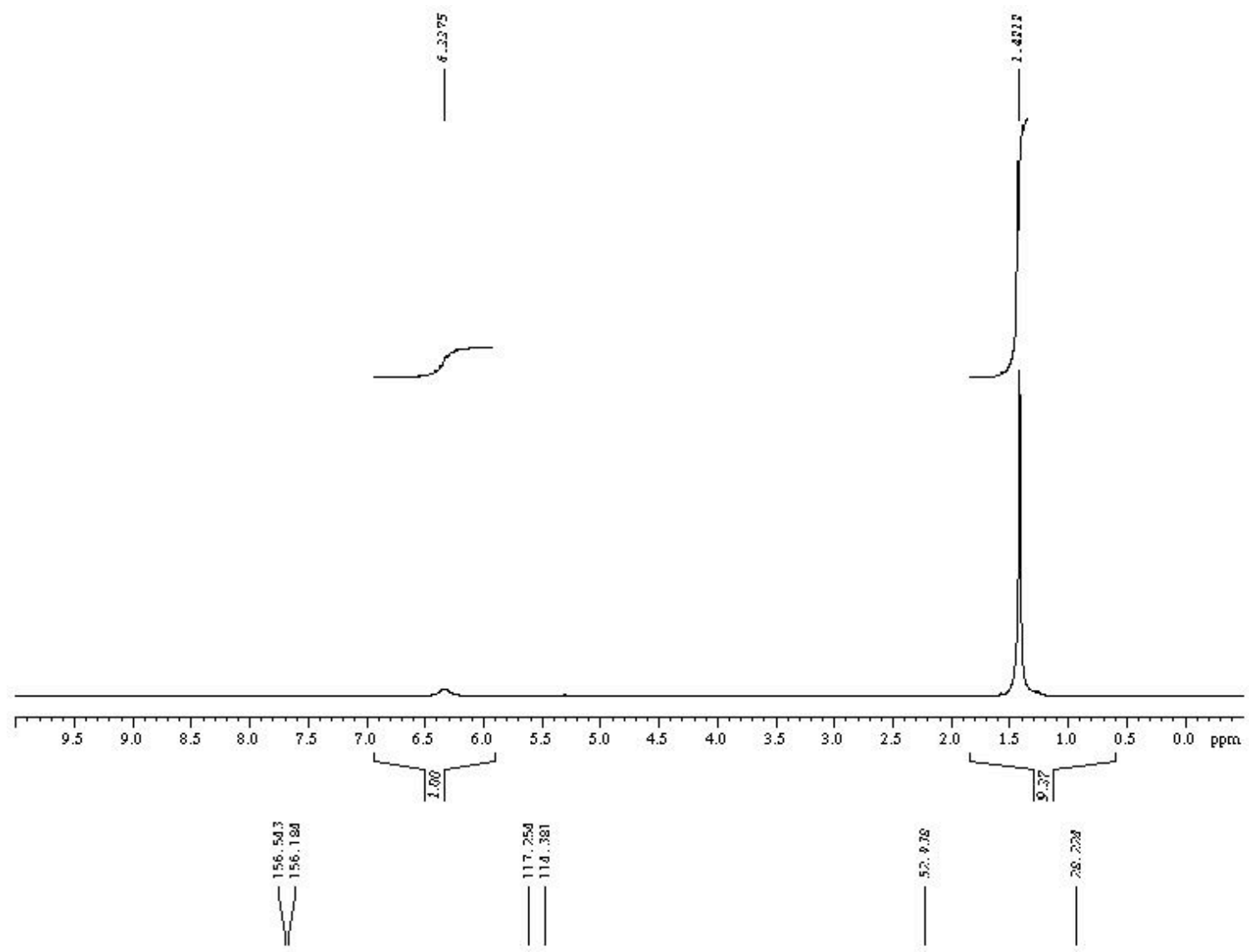

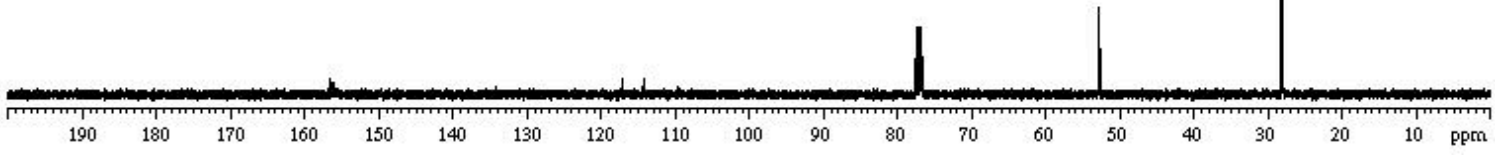


<smiles>CCCCNC(=O)CNC(=O)OC(C)(C)C</smiles>

11
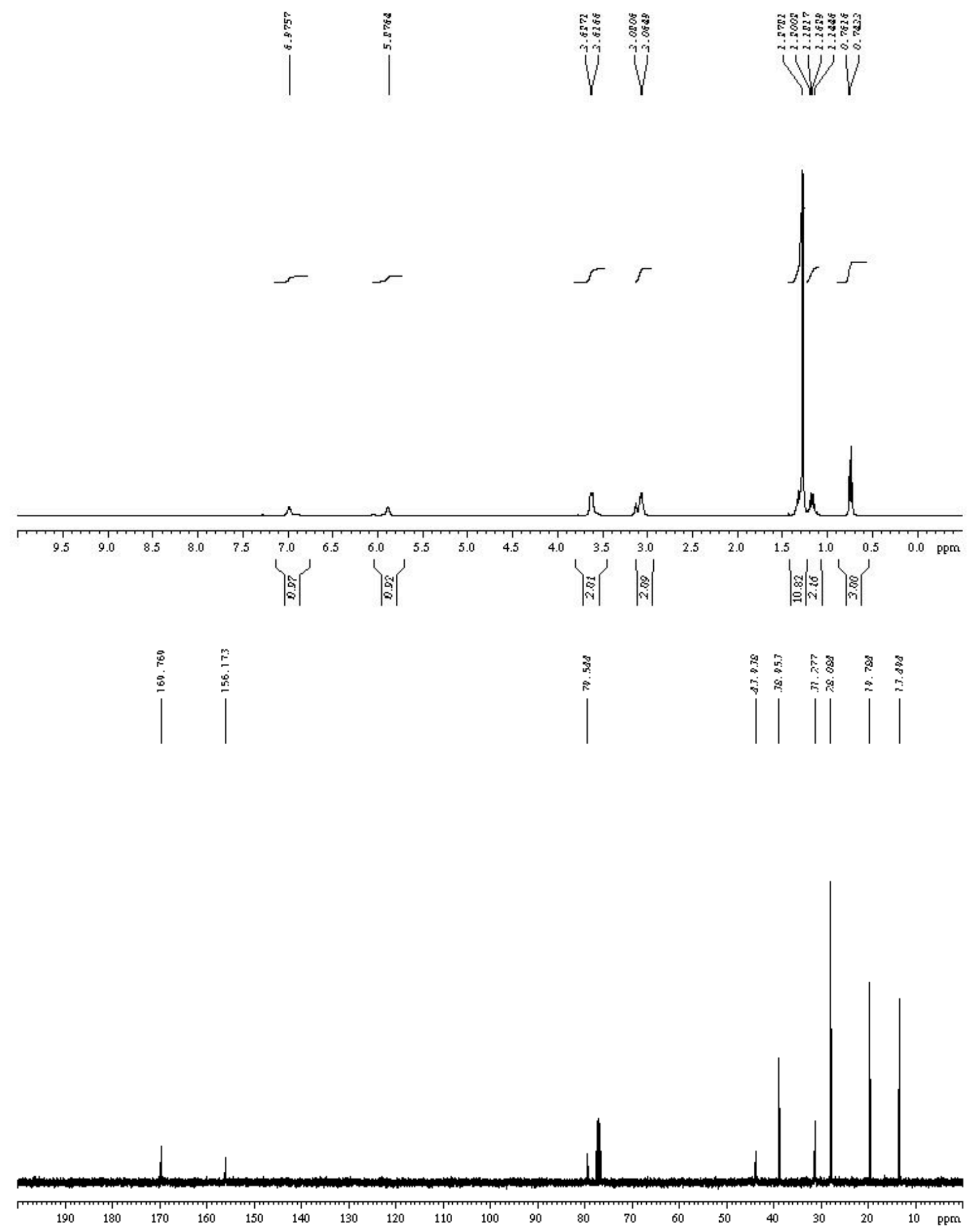


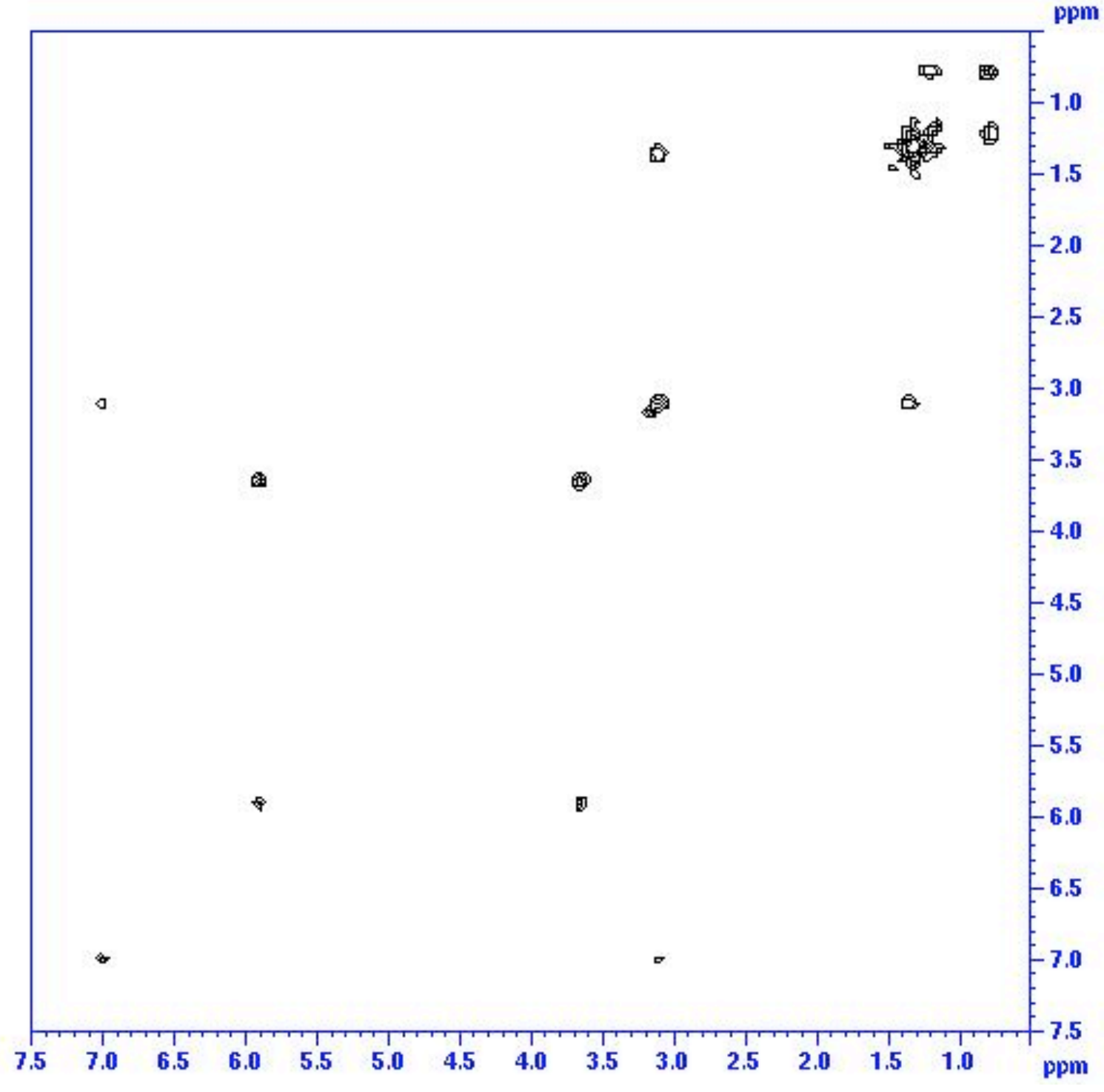


$\mathrm{tBuO}_{\substack{1 \\ \mathrm{Me}}}^{\mathrm{O}} \prod_{\mathrm{O}}^{\mathrm{I}} \overbrace{\mathrm{Bu}}^{\mathrm{O}}$

12

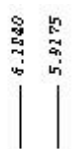

芶

i

,

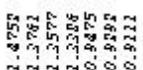

WV
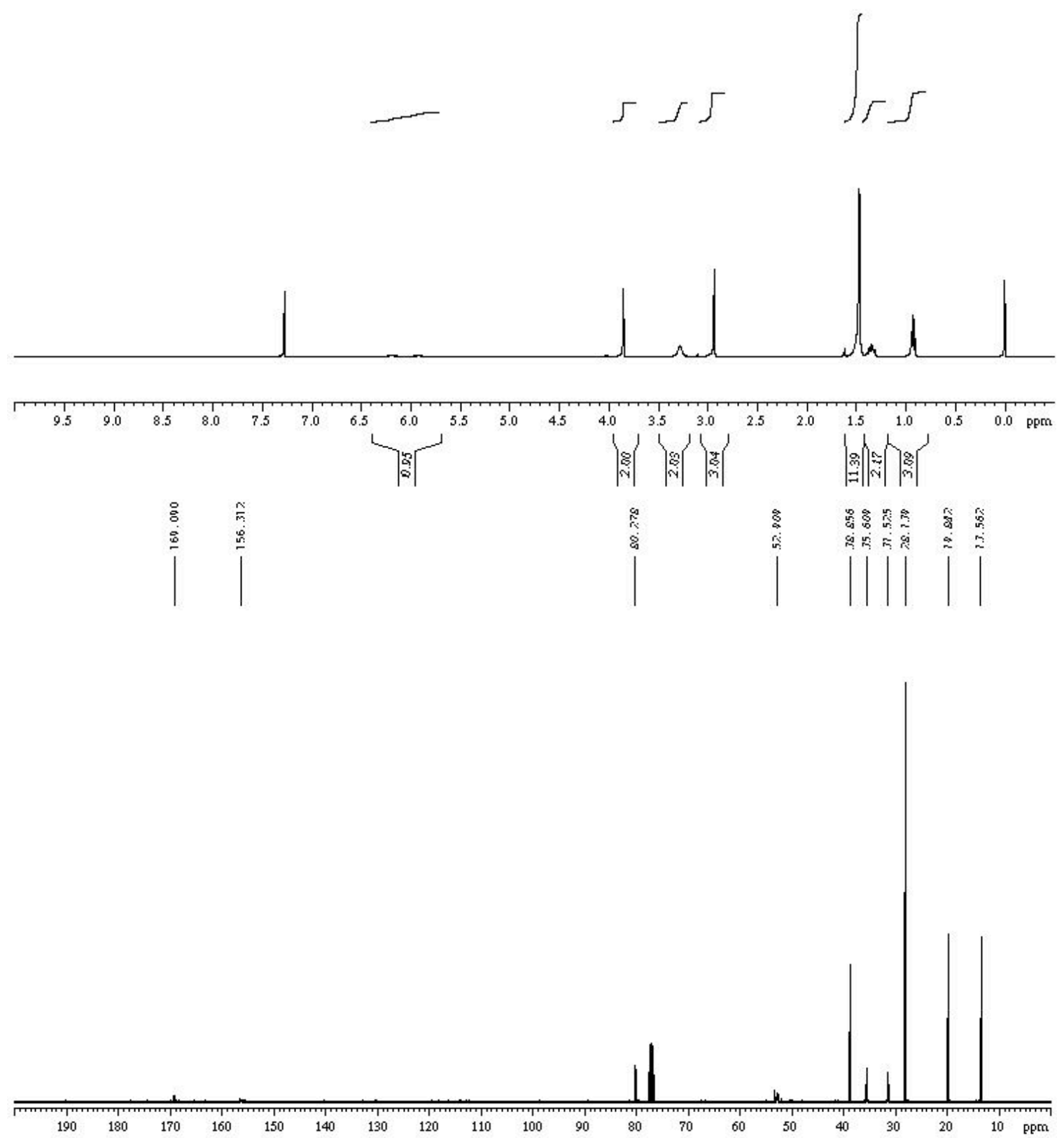


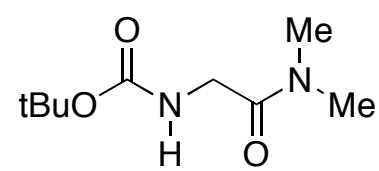

13
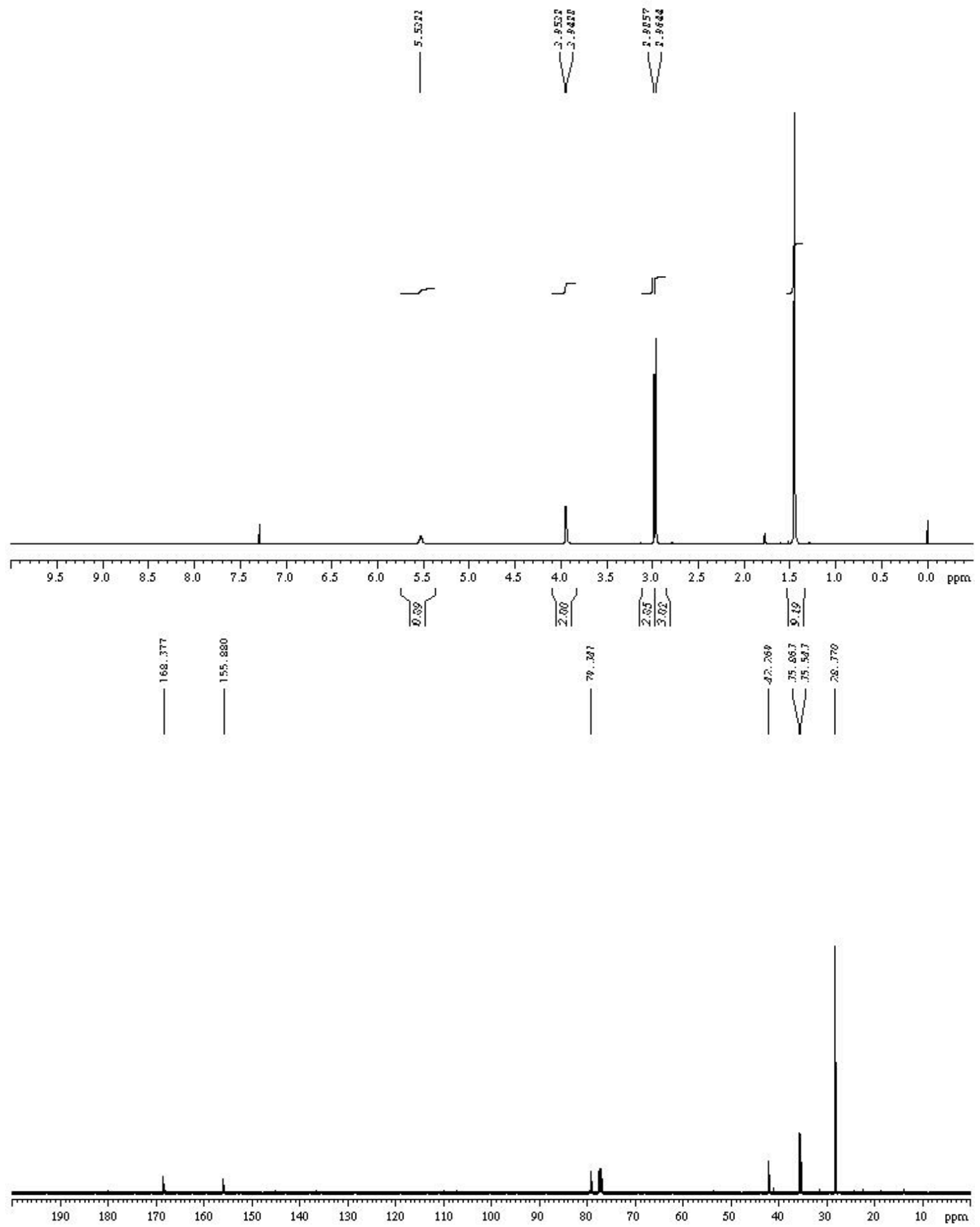
<smiles>CC(=O)NCCNC(=O)OCC(C)C</smiles>

\section{4}

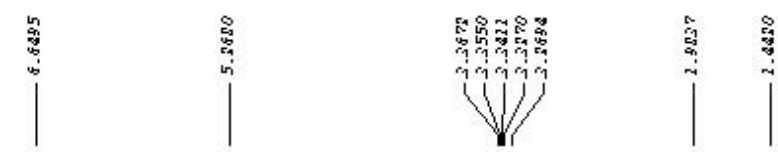

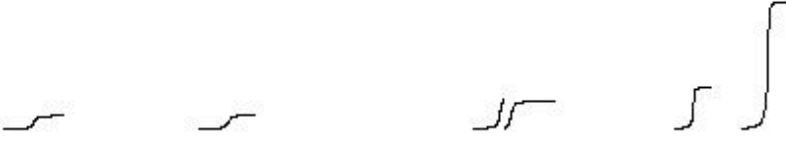
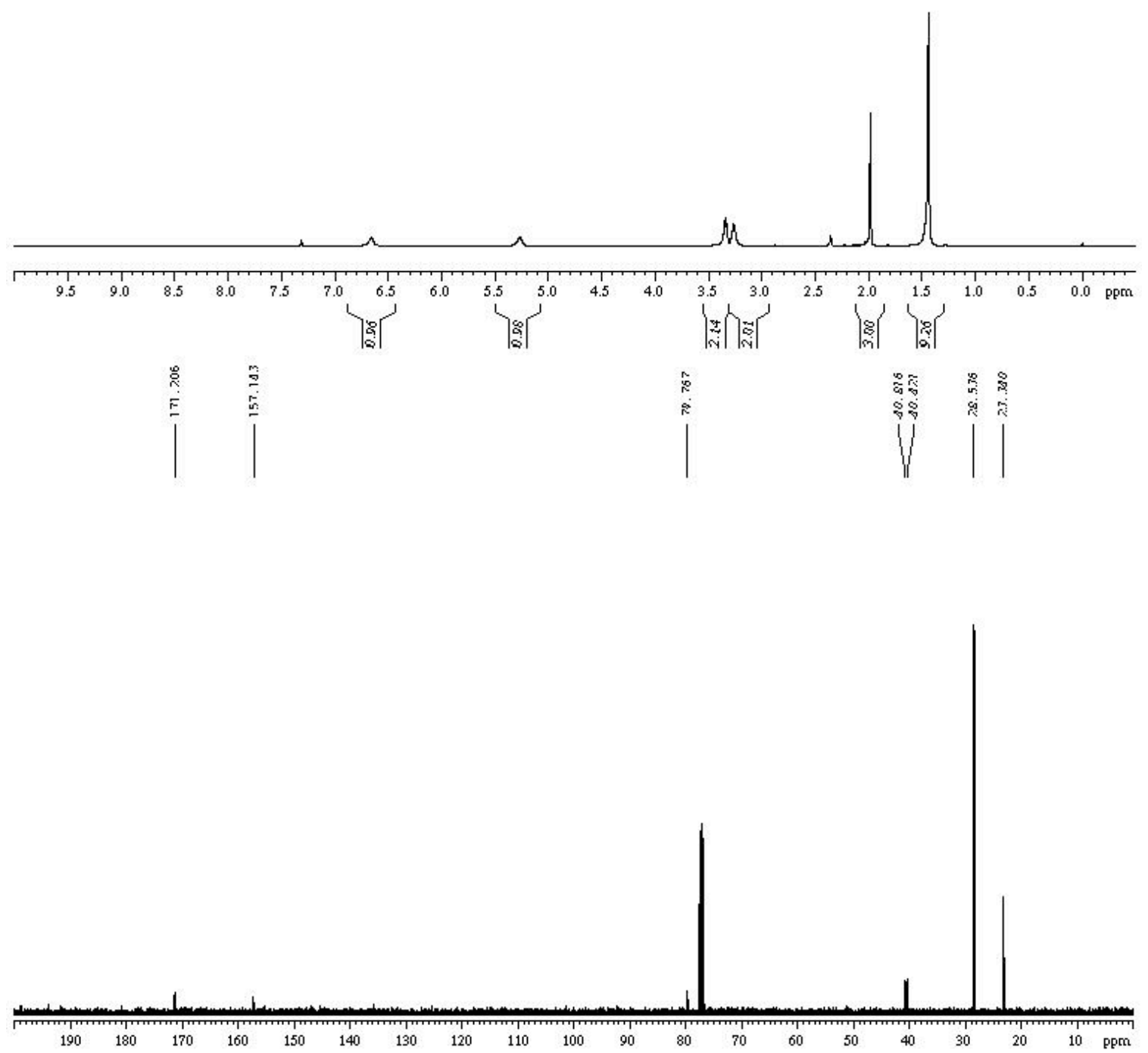
<smiles>CCCCNC(=O)CNC(=O)CNC(=O)OC(C)(C)C</smiles>

\section{5}

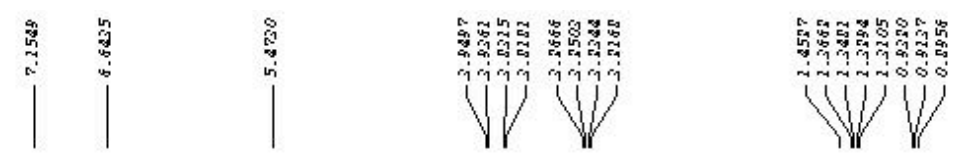

r- -2 T
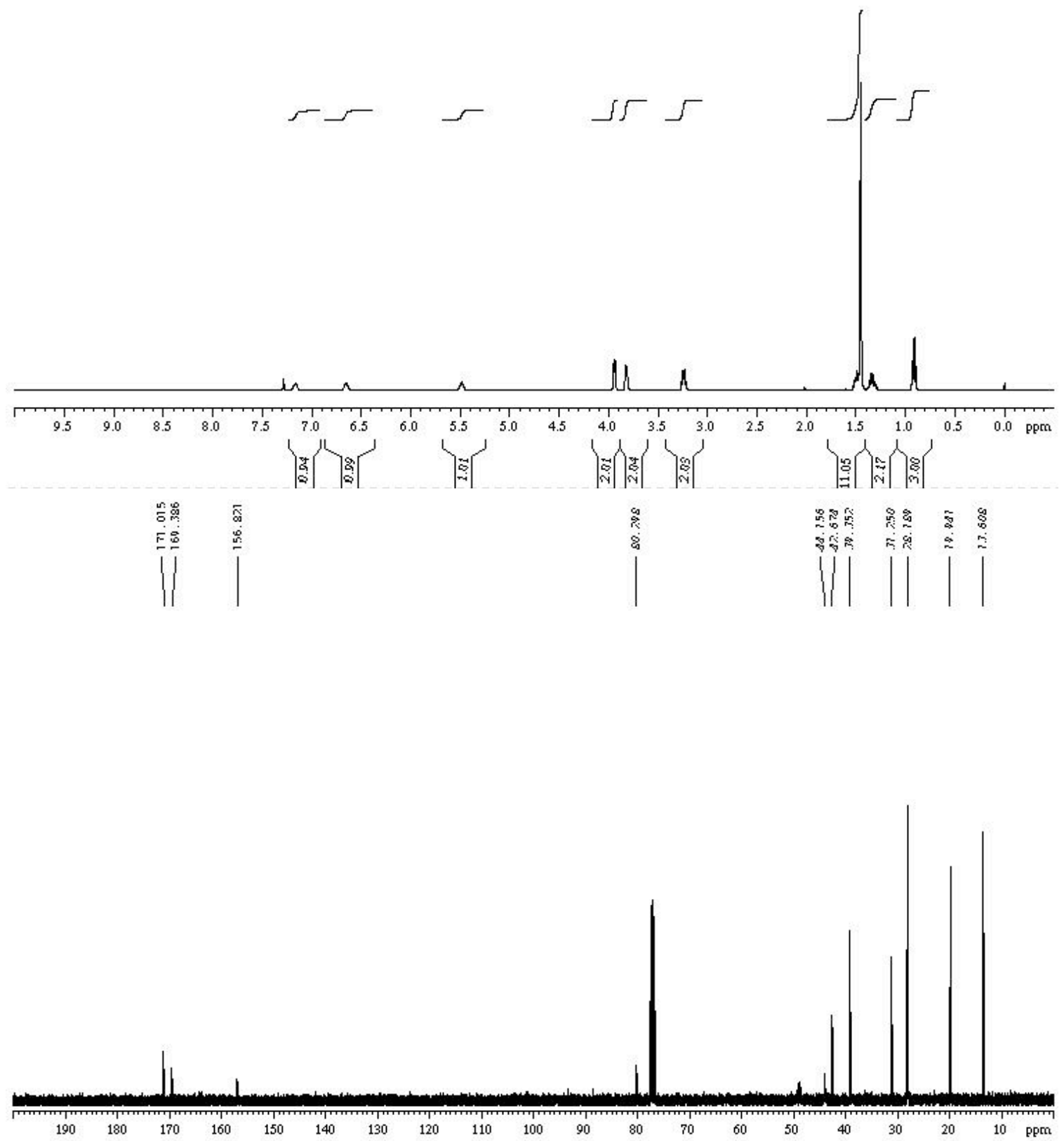


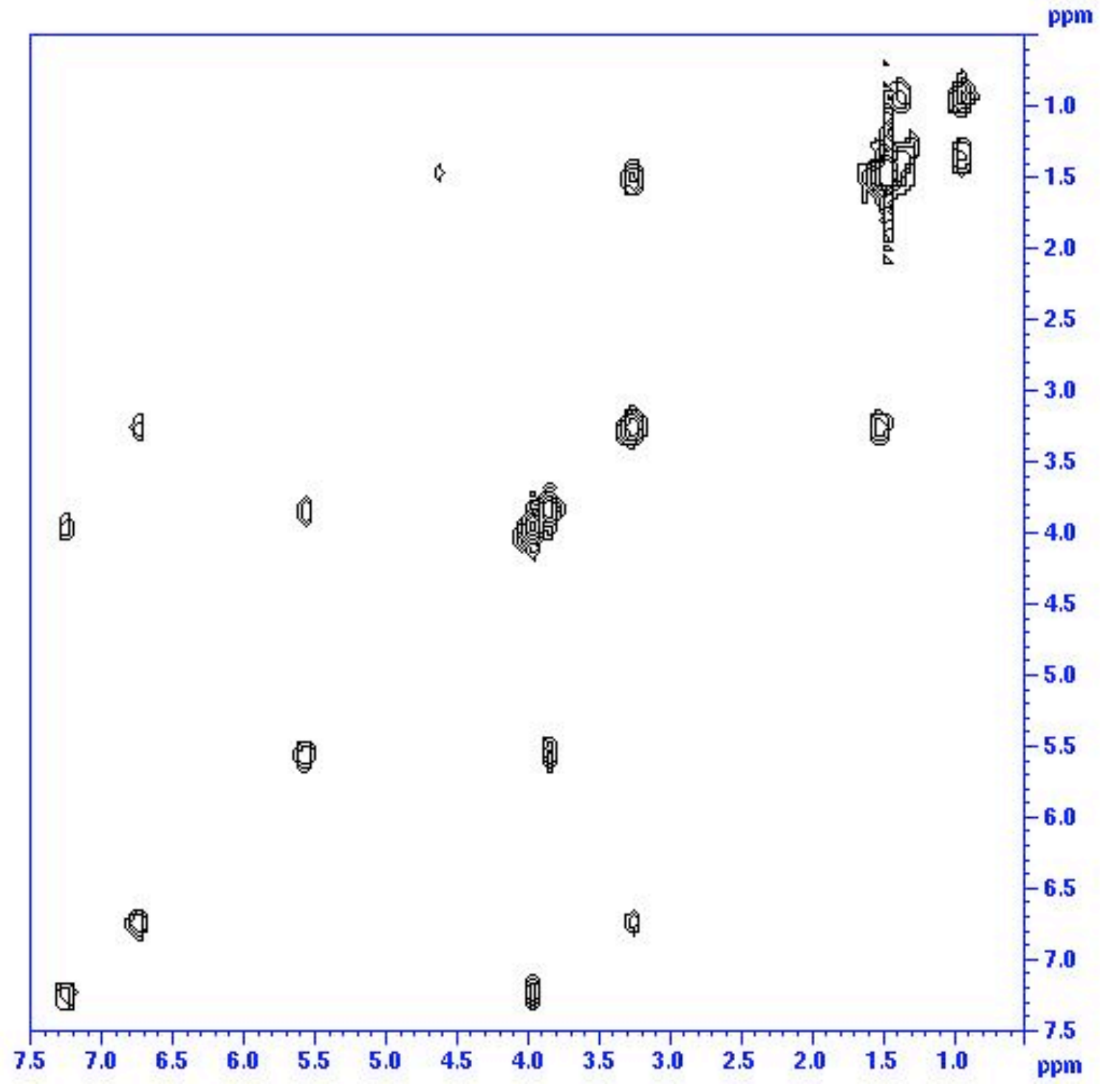

${ }^{1}$ Still, W. C.; Kahn, M.; Mitra, J. J. Org. Chem. 1978, 43, 2923-2924.

${ }^{2}$ Keller, O.; Keller, W. E.; van Look, G.; Wersin, G. Org. Synth. 1984, 63, 160-166.

${ }^{3}$ Khalil, E. M.; Subasinghe, N. L.; Johnson, R. L. Tetrahedron Lett. 1996, 37, 34413444 . 